NASA/TM-2006-214335
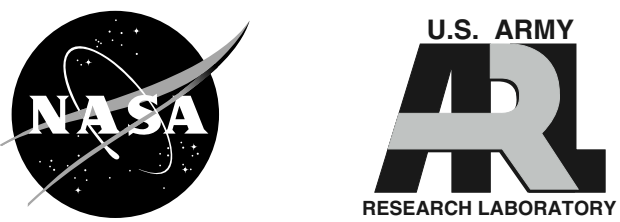

\title{
A Resonant Synchronous Vibration Based Approach for Rotor Imbalance Detection
}

Huageng Luo, Hector Rodriguez, and Darren Hallman

GE Global Research Center, Niskayuna, New York

David G. Lewicki

U.S. Army Research Laboratory, Glenn Research Center, Cleveland, Ohio 


\section{NASA STI Program . . . in Profile}

Since its founding, NASA has been dedicated to the advancement of aeronautics and space science. The NASA Scientific and Technical Information (STI) program plays a key part in helping NASA maintain this important role.

The NASA STI Program operates under the auspices of the Agency Chief Information Officer. It collects, organizes, provides for archiving, and disseminates NASA's STI. The NASA STI program provides access to the NASA Aeronautics and Space Database and its public interface, the NASA Technical Reports Server, thus providing one of the largest collections of aeronautical and space science STI in the world. Results are published in both non-NASA channels and by NASA in the NASA STI Report Series, which includes the following report types:

- TECHNICAL PUBLICATION. Reports of completed research or a major significant phase of research that present the results of NASA programs and include extensive data or theoretical analysis. Includes compilations of significant scientific and technical data and information deemed to be of continuing reference value. NASA counterpart of peer-reviewed formal professional papers but has less stringent limitations on manuscript length and extent of graphic presentations.

- TECHNICAL MEMORANDUM. Scientific and technical findings that are preliminary or of specialized interest, e.g., quick release reports, working papers, and bibliographies that contain minimal annotation. Does not contain extensive analysis.

- CONTRACTOR REPORT. Scientific and technical findings by NASA-sponsored contractors and grantees.
- CONFERENCE PUBLICATION. Collected papers from scientific and technical conferences, symposia, seminars, or other meetings sponsored or cosponsored by NASA.

- SPECIAL PUBLICATION. Scientific, technical, or historical information from NASA programs, projects, and missions, often concerned with subjects having substantial public interest.

- TECHNICAL TRANSLATION. Englishlanguage translations of foreign scientific and technical material pertinent to NASA's mission.

Specialized services also include creating custom thesauri, building customized databases, organizing and publishing research results.

For more information about the NASA STI program, see the following:

- Access the NASA STI program home page at http://www.sti.nasa.gov

- E-mail your question via the Internet to help@sti.nasa.gov

- Fax your question to the NASA STI Help Desk at 301-621-0134

- Telephone the NASA STI Help Desk at 301-621-0390

- Write to:

NASA STI Help Desk

NASA Center for AeroSpace Information 7121 Standard Drive Hanover, MD 21076-1320 
NASA/TM-2006-214335
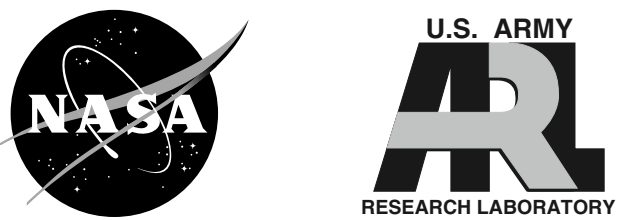

\section{A Resonant Synchronous Vibration Based Approach for Rotor Imbalance Detection}

Huageng Luo, Hector Rodriguez, and Darren Hallman

GE Global Research Center, Niskayuna, New York

David G. Lewicki

U.S. Army Research Laboratory, Glenn Research Center, Cleveland, Ohio

Prepared for the

47th Structures, Structural Dynamics, and Materials Conference cosponsored by the AIAA, ASME, ASCE, AHS, and ASC

Newport, Rhode Island, May 1-4, 2006

National Aeronautics and

Space Administration

Glenn Research Center

Cleveland, Ohio 44135 


\section{Acknowledgments}

The authors gratefully acknowledge the leadership and support from Dennis Corbly of GE Aircraft Engines, Cincinnati, Ohio; William C. Emmerling and Donald Altobelli of the Federal Aviation Administration, William J. Hughes Technical Center, Atlantic City, New Jersey; Leo Fila and Greg Muschlitz of Naval Air Systems Command, Patuxent River, Maryland; Silvia Seng and Chuck Frankenberger of the Naval Air Warfare Center, Weapons Division, China Lake, California.

This work was sponsored by the Fundamental Aeronautics Program at the NASA Glenn Research Center.

Level of Review: This material has been technically reviewed by technical management.

Available from

NASA Center for Aerospace Information 7121 Standard Drive

Hanover, MD 21076-1320
National Technical Information Service 5285 Port Royal Road Springfield, VA 22161 


\title{
A Resonant Synchronous Vibration Based Approach for Rotor Imbalance Detection
}

\author{
Huageng Luo, Hector Rodriguez, and Darren Hallman \\ GE Global Research Center \\ Niskayuna, New York 12309 \\ David G. Lewicki \\ U.S. Army Research Laboratory \\ Glenn Research Center \\ Cleveland, Ohio 44135
}

\begin{abstract} test has been carried out and the results are reported.

\section{Nomenclature}

C complex constant

$C_{2} \quad$ mass imbalance parameter, $\frac{U_{m}}{m \omega_{0}^{2}}$

$C_{3} \quad$ crack induced imbalance parameter, $\frac{K_{C}}{m \omega_{0}^{2}}$

$c \quad$ viscous damping

$D_{i} \quad$ complex constants

$j \quad$ complex symbol, $j=\sqrt{-1}$

$K_{C} \quad$ crack induced imbalance constant

$k \quad$ stiffness

$m \quad$ equivalent mass of a system

$Y \quad$ Laplace transform of $y(t) . Y(j \omega)=\left.L[y(t)]\right|_{s=j \omega}$

$y(t) \quad$ time domain displacement response

$U_{C} \quad$ crack induced imbalance, $U_{C}=K_{C} \omega^{2}$

$U_{m} \quad$ mass imbalance in frequency domain

$u_{m} \quad$ amplitude of the imbalance, $\left|U_{m}\right|$

$\theta \quad$ phase angle of the imbalance

$\xi_{0} \quad$ damping ratio of a single-degree-of-freedom system the system, $\frac{c}{2 \omega_{0} m}$

$\omega \quad$ shaft speed

$\omega_{0} \quad$ natural frequency of a single-degree-of-freedom system, $\sqrt{\mathrm{k} / \mathrm{m}}$
\end{abstract}

This paper presents a methodology of detecting rotor imbalances, such as mass imbalance and crack-induced imbalance, using shaft synchronous vibrations. An iterative scheme is developed to identify parameters from measured synchronous vibration data. A detection system is integrated by using state-of-the-art commercial analysis equipment. A laboratory rotor test rig is used to verify the system integration and algorithm validation. A real engine

\section{Introduction}

In rotating machinery, it has been well established that mass-induced (ref. 1) synchronous vibration is proportional to the square of the rotational speed, i.e., $\omega^{2}$, in the region where $\omega<<\omega_{0}$, where $\omega_{0}$ is the first resonant frequency of the machinery system. It has also been established that radial-axial cracks (refs. 2 and 3 ) in the rotating 
disk or shaft can cause a synchronous vibration that is proportional to $\omega^{4}$, under the same assumption of $\omega<<\omega_{0}$. Several groups have developed detection systems based on these assumptions (refs. 4 and 5). Unfortunately, in reality, there are several major difficulties in implementing these traditional algorithms:

1. It is difficult to satisfy the $\omega<<\omega_{0}$ condition without significantly reducing the signal-to-noise-ratio, because the first natural frequency in many rotating machinery systems is very low. In soft-mounted rotor systems, the first natural frequency can be so low that it prevents such monitoring systems from getting meaningful results.

2. It is difficult to simplify real rotating machinery into a single degree of freedom (SDOF) system.

Additionally, the vibration sensors are usually mounted on the bearing case or the engine case, so that additional structural resonances, besides rotor-shaft resonances, may be picked up, thus complicating the simple polynomial relationship.

In this research, a new algorithm is developed for mass imbalance and crack detection in a multi-degree of freedom (MDOF) rotating machinery system. The proposed method takes advantage of high signal-to-noise-ratio in the neighborhood of resonant frequencies in synchronous vibration, thus it is expected to have better accuracy in imbalance detection.

\section{Theory}

In the simplest possible model for rotor vibration analysis, the system is described by a spring-mass-damper system as shown in figure 1. With this model, the system has to be either a rigid rotor and disk with a flexible bearing, or a flexible mass-less rotor shaft with a rigid bearing and single rigid disk. Under these assumptions, the frequency domain displacement response due to a mass imbalance can be expressed as

$$
Y(j \omega)=\frac{U_{m} \omega^{2}}{m\left(\omega_{0}^{2}-\omega^{2}+2 j \xi_{0} \omega_{0} \omega\right)}
$$

The presence of certain cracks in the rotor disk introduce similar vibration to that caused by a mass imbalance, i.e.,

$$
Y(j \omega)=\frac{U_{C} \omega^{2}}{m\left(\omega_{0}^{2}-\omega^{2}+2 j \xi_{0} \omega_{0} \omega\right)}
$$

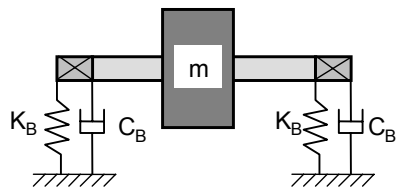

Rigid Rotor, Flexible Bearing

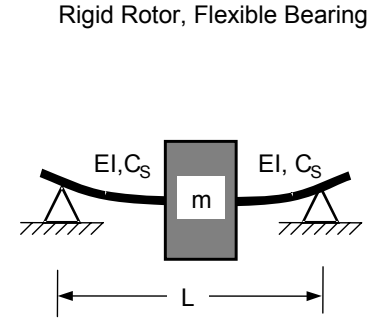

Rigid Bearing, Flexible Rotor

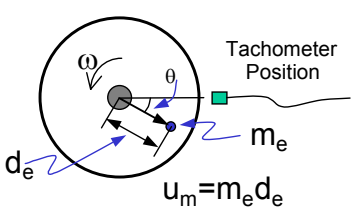

Mass Unbalance
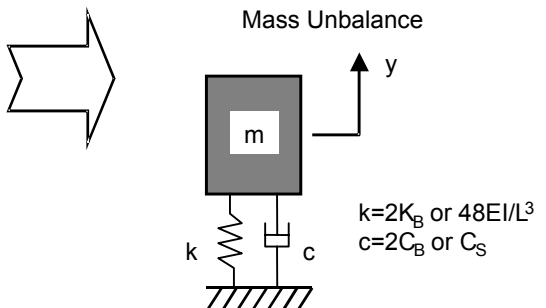

Single-degree-freedom Dynamics Model
$\mathrm{C}_{\mathrm{B}}=$ bearing damping

$\mathrm{C}_{\mathrm{S}}=$ shaft damping

$\mathrm{d}_{\mathrm{e}}=$ distance

$\mathrm{E}=$ shaft modulus

$I=$ shaft moment of inertia

$\mathrm{K}_{\mathrm{B}}=$ bearing stiffness

$\mathrm{M}_{\mathrm{e}}=$ unbalance mass

$\mathrm{m}=$ rotor mass

$\mathrm{u}_{\mathrm{m}}=$ unbalance

$\theta=$ angular position

$\omega=$ speed

Figure 1.- SDOF rotor dynamics modeling. 
where $U_{C}$ is the crack induced imbalance. It is a complex variable in the frequency domain. According to reference 3 and finite element verification in reference $6, U_{C}$ is a function of rotational speed, crack length, and rotor disk geometry, or more precisely,

$$
U_{C}=K_{C} \omega^{2}=K_{C}(\text { crack, disk }) \omega^{2}
$$

Thus, in presence of both mass and crack-induced imbalances, the rotating system possesses a displacement vibration response format as

$$
Y(j \omega)=\frac{U_{m} \omega^{2}}{m\left(\omega_{0}^{2}-\omega^{2}+2 j \xi_{0} \omega_{0} \omega\right)}+\frac{K_{C} \omega^{4}}{m\left(\omega_{0}^{2}-\omega^{2}+2 j \xi_{0} \omega_{0} \omega\right)}
$$

In the region where $\omega<<\omega_{0}$, equation (4) can be simplified as

$$
Y(j \omega)=\frac{U_{m} \omega^{2}}{m \omega_{0}^{2}}+\frac{K_{C} \omega^{4}}{m \omega_{0}^{2}}=C_{2} \omega^{2}+C_{3} \omega^{4}
$$

where

$$
C_{2}=\frac{U_{m}}{m \omega_{0}^{2}} ; \quad C_{3}=\frac{K_{C}}{m \omega_{0}^{2}}
$$

are the imbalance and system parameter related complex constants. For a rotating system operated in a speed range between resonant frequencies, an improved detection methodology can be found in reference 7 .

Real rotating machinery can rarely be modeled as a simple system. It is usually a distributed system with infinitely many DOFs and with low first resonance frequencies. In such cases, the system response has to be modified into a multi-degree-of-freedom (MDOF) format. Assuming the system has distinct natural frequencies, for simplicity, we have the displacement response as

$$
Y(j \omega)=\sum_{i=1}^{\infty} \frac{U_{m i} \omega^{2}}{m_{i}\left(\omega_{i}^{2}-\omega^{2}+2 j \xi_{i} \omega_{i} \omega\right)}+\sum_{i=1}^{\infty} \frac{K_{C i} \omega^{4}}{m_{i}\left(\omega_{i}^{2}-\omega^{2}+2 j \xi_{i} \omega_{i} \omega\right)}
$$

Provided that the rotor is operated in the frequency range $\omega=\left[\omega_{01}, \omega_{02}\right]$, and

$$
\left\{\begin{array}{l}
\omega_{01}<\omega<\omega_{02} \\
\omega_{k}<\omega_{01}<\omega_{k+1} \text { and } \omega_{k+l}<\omega_{02}<\omega_{k+l+1} \\
k \geq 1 \text { or } \omega_{k}=0 \\
l \geq 1
\end{array}\right.
$$

and further supposing that all the resonant frequencies are well separated such that the cross coupling from modes outside the operational range are in a simple form, then equation (7) can be expressed into a finite summation as

$$
Y(j \omega)=\sum_{i=k}^{l} \frac{U_{m i} \omega^{2}}{m_{i}\left(\omega_{i}^{2}-\omega^{2}+2 j \xi_{i} \omega_{i} \omega\right)}+\sum_{i=k}^{l} \frac{K_{C i} \omega^{4}}{m_{i}\left(\omega_{i}^{2}-\omega^{2}+2 j \xi_{i} \omega_{i} \omega\right)}+C
$$

where $C$ is a complex constant to account for the influence from other modes. For a given response curve, $\omega_{i}$ and $\xi_{i}$, $i=k, k+1, \ldots, l$, can be approximated by identifying the peak location and by the half power method to get initial estimations. Then an iterative method, such as the diagram shown in figure 2, can be implemented to improve the accuracy and to solve for relative modal excitations of $\frac{U_{m i}}{m_{i}}$, and $\frac{K_{C i}}{m_{i}}$. 


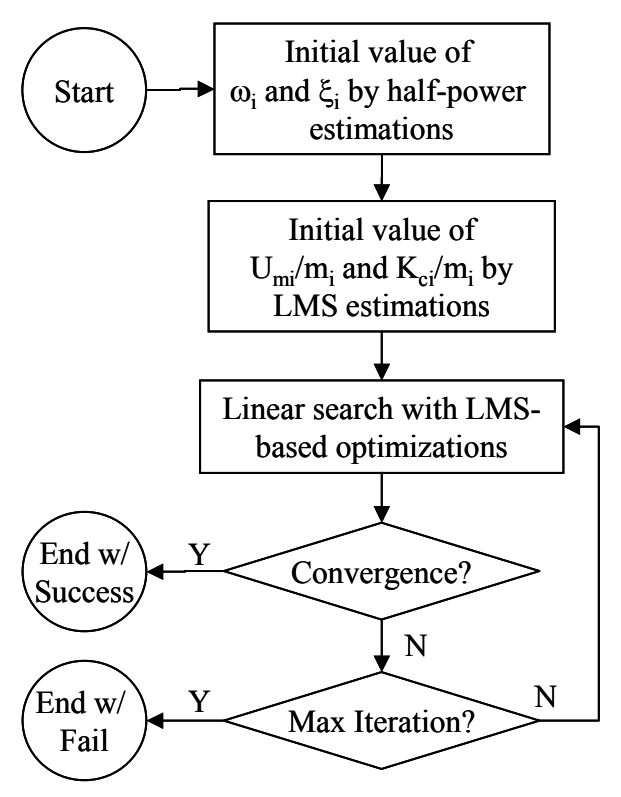

Figure 2.-Diagram of solving imbalances.

In cases when accelerometers are used as sensors, equation (9) needs to be modified as

$$
\begin{aligned}
Y(j \omega) & =\sum_{i=k}^{l} \frac{U_{m i} \omega^{4}}{m_{i}\left(\omega_{i}^{2}-\omega^{2}+2 j \xi_{i} \omega_{i} \omega\right)}+\sum_{i=k}^{l} \frac{K_{C i} \omega^{6}}{m_{i}\left(\omega_{i}^{2}-\omega^{2}+2 j \xi_{i} \omega_{i} \omega\right)} \\
& +C+\sum_{i=k}^{l} \frac{D_{i} \omega^{2}}{m_{i}\left(\omega_{i}^{2}-\omega^{2}+2 j \xi_{i} \omega_{i} \omega\right)}
\end{aligned}
$$

where $C$ is a complex constant representing the influence from other modes, and $D_{i}$ s are used to account for responses due to random excitations imposed to the rotating system, such as environmental excitations and nonlinear interactions of the system.

\section{System Integration}

In an accelerated test, the engine ramp-up (or coast-down) process is actually taking place in a very short time. It is very important to have a system that can handle multi-channel simultaneous data acquisition, synchronous data processing, condition monitoring, and data management in a short time. Additionally, the signals from such tests are usually noisy, thus it is critical to have a processing technique which can improve the signal-to-noise-ratio.

To meet the engine requirements, the Pulse system by B\&K was selected as the hardware platform. The Production Test Advisor (PTA) by Signalysis, Inc. was selected as the database management system. A MATLAB (The MathWorks, Inc.) based post-processing system was developed in-house at GE and integrated into the system for real-time health monitoring. A brief system diagram is shown in figure 3.

\section{Sensors}

Sensors include vibration transducers and a tachometer signal. For synchronous vibration detection, any vibration sensors, such as accelerometers, velocity sensors, or displacement probes, can be used. Appropriate signal conditioners are needed for the corresponding sensors used. A once per revolution ( $1 / \mathrm{rev})$ signal from the rotating shaft is also needed for analysis and order extraction. 


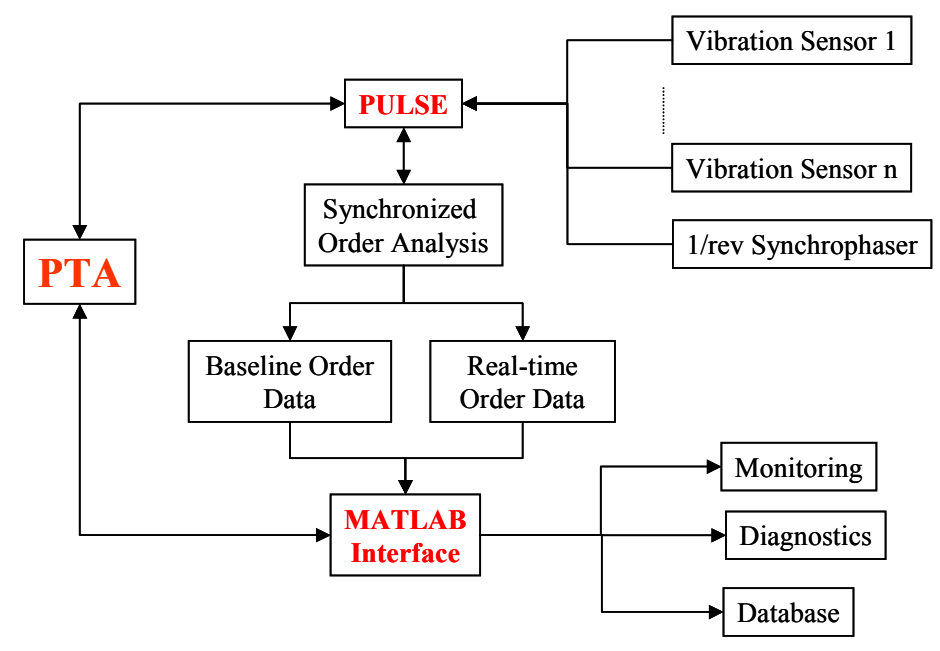

Figure 3.- System integration diagram.

\section{Front-end}

The front-end is the raw data collector and signal pre-processor. The B\&K Pulse system was selected as the front-end for our system. The Pulse system is a real-time multi-analysis platform for vibration and sound analyses. The order analyzer of the Pulse system was activated in the integrations. In order to improve the signal-to-noise ratio, a synchronous averaging technique was also employed. The 1st order synchronous vibration was the main focus in the system. Multiple orders were monitored and processed in real time.

\section{Data Management}

Data management was carried out by the PTA (Product Test Adviser). PTA is a special version of SigQC developed by Signalysis Inc. SigQC was originally designed for manufacturer quality assurance. It is a production line test that responds to the demand among manufacturers to automate a process for accepting or rejecting units on the assembly line based on measured noise and vibration data. SigQC provides basic statistics, criteria, strategies and pass/fail methods. The major functions of the PTA include Database Management (Database tree) and Production Line Interface (traffic control).

\section{MATLAB Interface}

The PTA provides basic statistics, criteria, strategies and pass/fail methods, but it is very difficult to use these basic functions to construct a diagnostic algorithm for crack detection. MATLAB codes for mass and crack imbalance detection functions were developed according to equation (9) or equation (10) for resonant synchronous vibrations. The codes were integrated into the crack detection system by utilizing the interface provided in the SigQC.

\section{Small Rotor Test}

To verify the crack detection system integration and algorithms, a Bently Nevada RK 4 rotor kit was used as a test bench.

\section{A. Setup}

The test rig diagram and instrument setup are shown in figures 4 and 5, respectively. A single rotor disk with two bearings was used in the setup. The rotor disk has a weight of $810 \mathrm{~g}$ and balance slots at a radius of $30.5 \mathrm{~mm}$ in $22.5^{\circ}$ increments around the circumference (see fig. 6). The rotor shaft has a diameter of $10 \mathrm{~mm}$ and the bearing span is $400 \mathrm{~mm}$ with an additional $200 \mathrm{~mm}$ overhang. With such a setup, the fundamental frequency of the system is at $2000 \mathrm{rpm}$. Modal tests indicate that the second bending resonance is at about 10,000 rpm. 


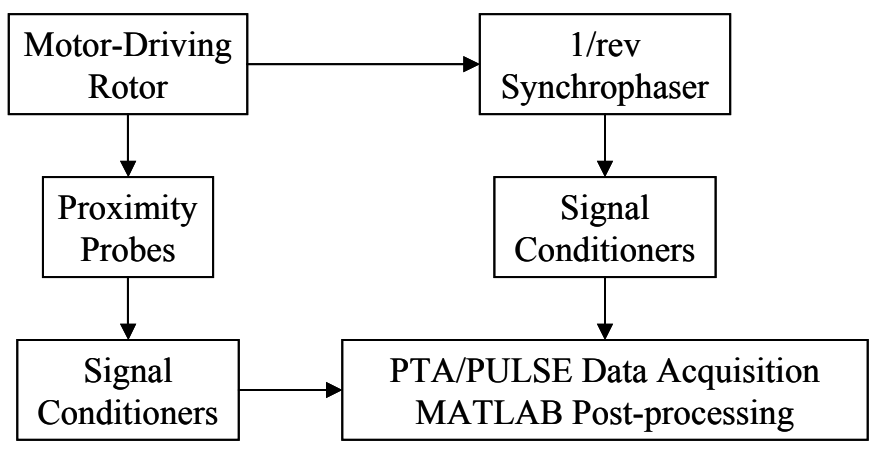

Figure 4.-Small rotor rig test diagram.

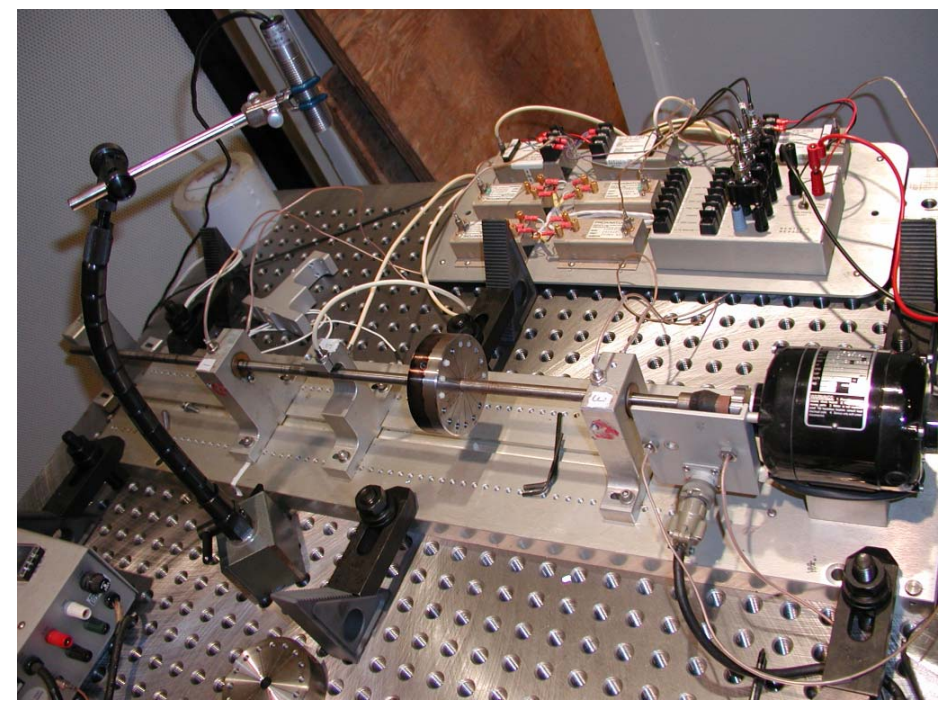

Figure 5.-Small rotor test kit.

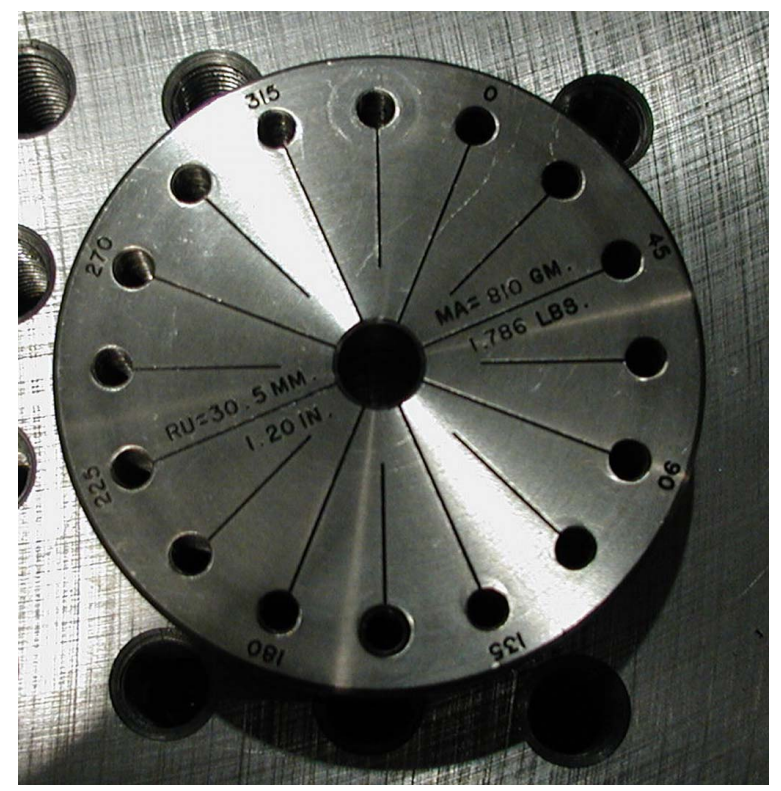

Figure 6.- Rotor kit disk with balance slots. 
Proximity probes were used as the signal pick-ups. Sensor \#1 (vib1) was in the vertical direction, while sensor \#2 (vib2) was in the horizontal direction. A typical synchronous response of the system is shown in figures 7 and 8 , respectively.

Nylon set screws, instead of steel ones, were used as imbalance weights to improve the imbalance resolution. As a result, the smallest imbalance unit was $3.416 \mathrm{~g}-\mathrm{mm}$. The disk $0^{\circ}$ position was aligned with the center of the notch on the rotor shaft. A mechanical 1/rev signal (shaft notch detected by proximity probe) was used as the trigger. The rising edge of the signal was used in the trigging, which turned out to be the trailing edge of the shaft notch. Later a laser calibration indicated that the actual triggering point corresponds to approximately the $30^{\circ}$ rotor disk circumferential position.
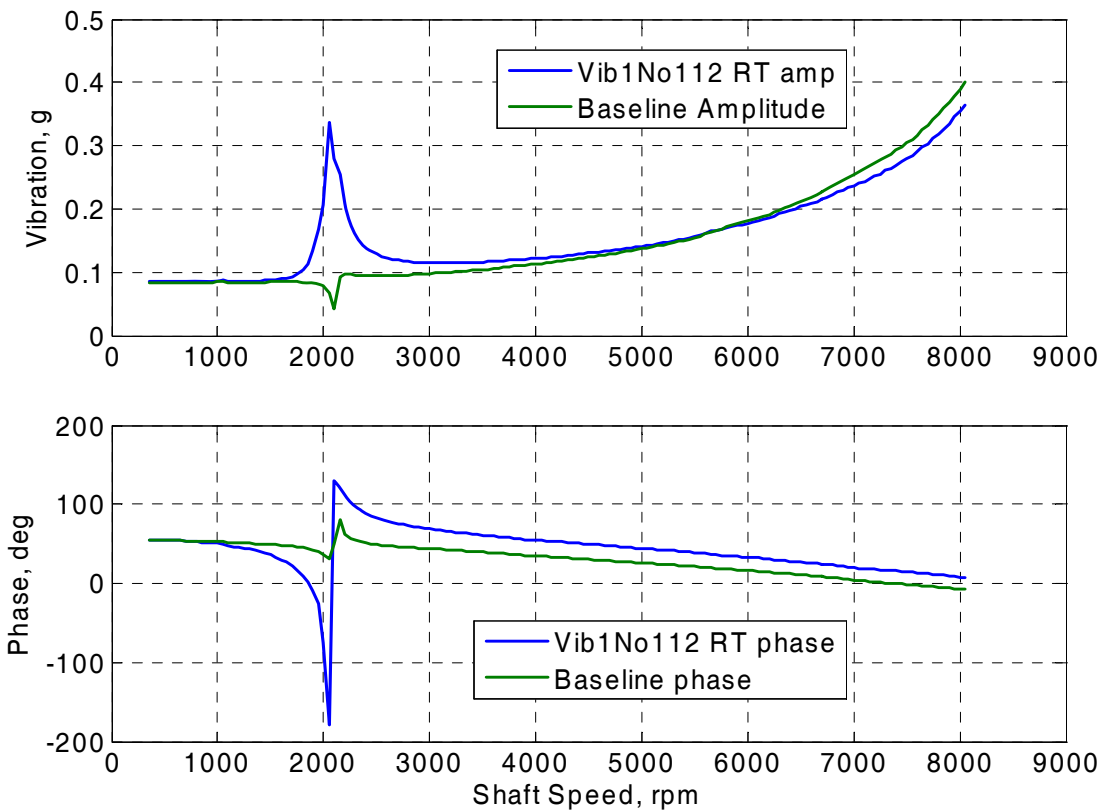

Figure 7.-Typical synchronous response, vertical.
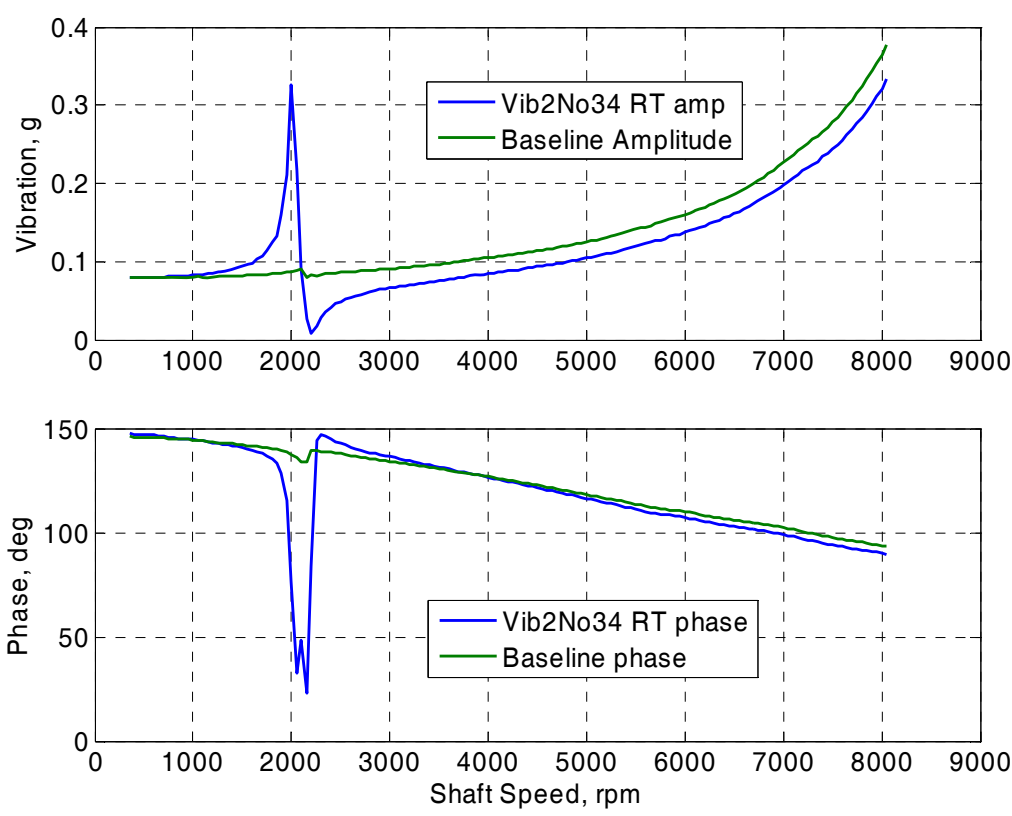

Figure 8.-Typical synchronous response, horizontal. 


\section{B. Tests}

The initial system was balanced to the calibration system capacity. To verify the system integration and algorithms, imbalances were added at two circumferential positions, nominally $0^{\circ}$ and $90^{\circ}$ on the rotor disk, one at a time. The $1 /$ rev signal comes from a notch on the shaft near the $0^{\circ}$ mark. The actual notch is a filing-off of the shaft, which covers approximately $60^{\circ}$ of circumference. According to the calibration, the imbalance correspond to approximately $30^{\circ}$ and $120^{\circ}$ with respect to the $1 /$ rev trigger. At each circumferential location, 4 different imbalance weights were added: 1, 2, 3, and 4 set screws, which correspond to 3.416, 6.832, 10.248, and $13.664 \mathrm{~g}-\mathrm{mm}$ imbalances.

The motor speed was controlled such that the synchronous data acquisition between 350 to $8050 \mathrm{rpm}$ with $50 \mathrm{rpm}$ step was guaranteed. Ten runs were recorded at the balanced state and a baseline was constructed based on these balanced runs. For each imbalance case, five repeated runs were recorded for further analysis.

\section{Data Reduction}

In the imbalanced runs, the baseline data were removed from each real time data acquisition by complex subtractions. The complex residue data were then fed in to the MATLAB based parameter identification algorithm through an iterative scheme. Both the amplitude and the phase of the imbalance were identified. Since the rotor shaft first bending was the dominant mode, a single-degree-freedom method was used, though multi-degree-freedom methods are also available in the codes.

Typical parameter identification results are shown in figure 9. As a result of the high signal-to-noise-ratio near resonance, good curve-fitting results are usually achieved in both the amplitude and the phase. The fitting parameter is a complex number (fig. 10); its amplitude is proportional to the additional imbalance relative to the baseline, while its phase indicates the circumferential location of the additional imbalance with respect to the trigger.
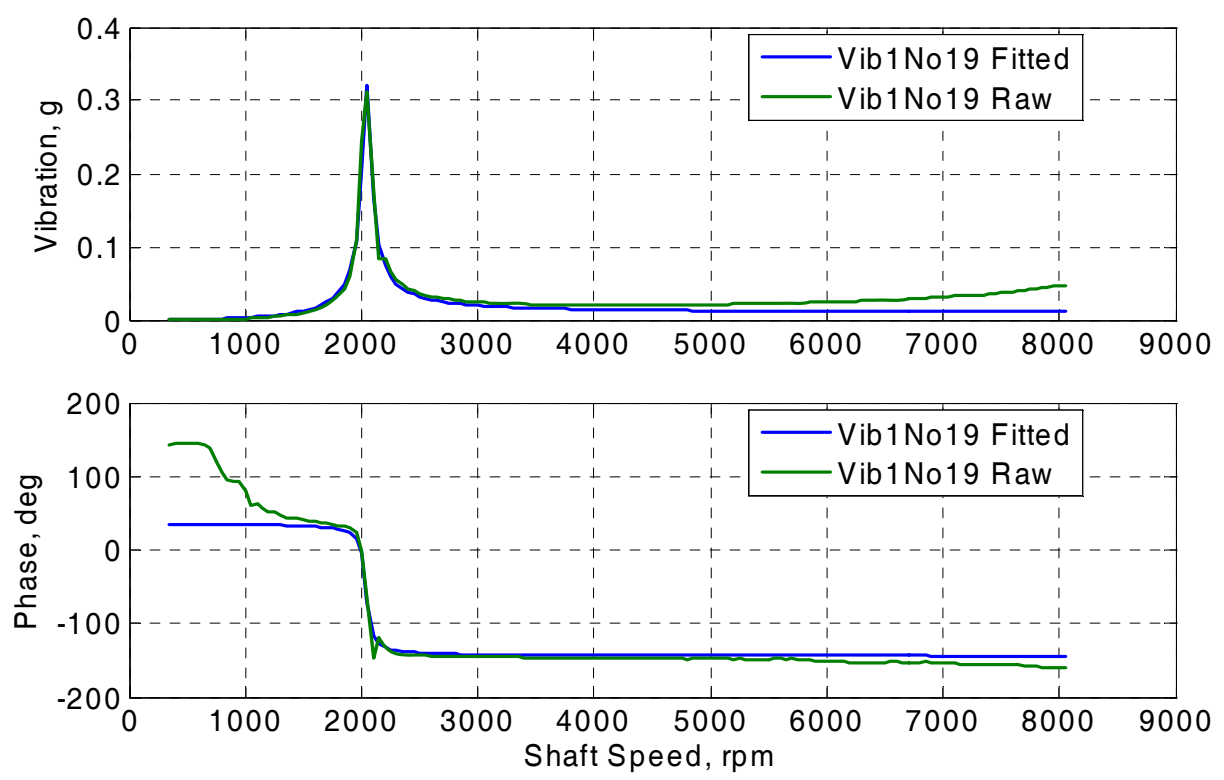

Figure 9.-SDOF curve-fitting on the complex residue. 


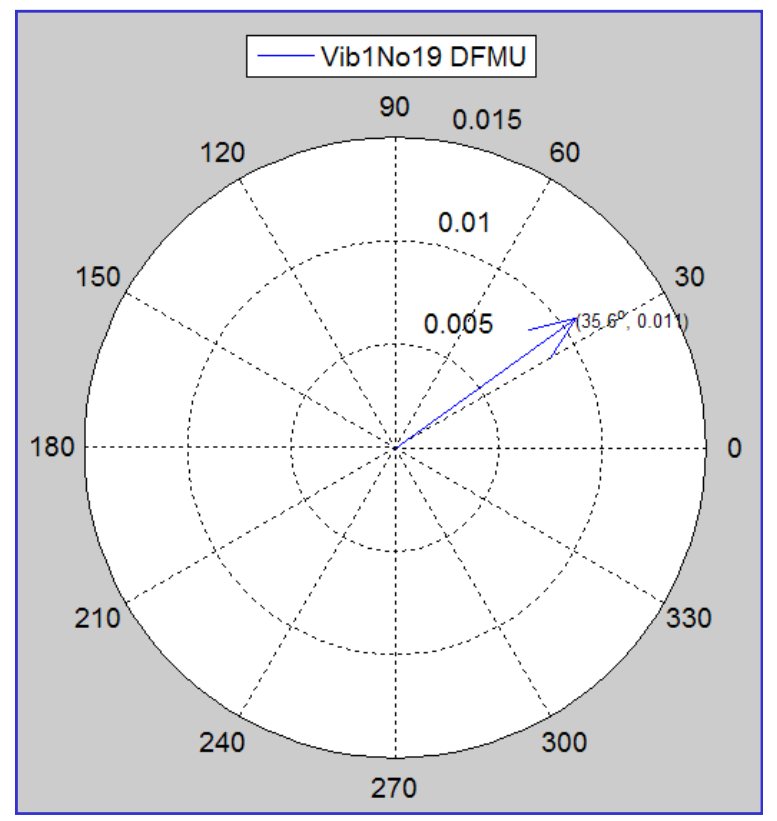

Figure 10.- Identified vector.

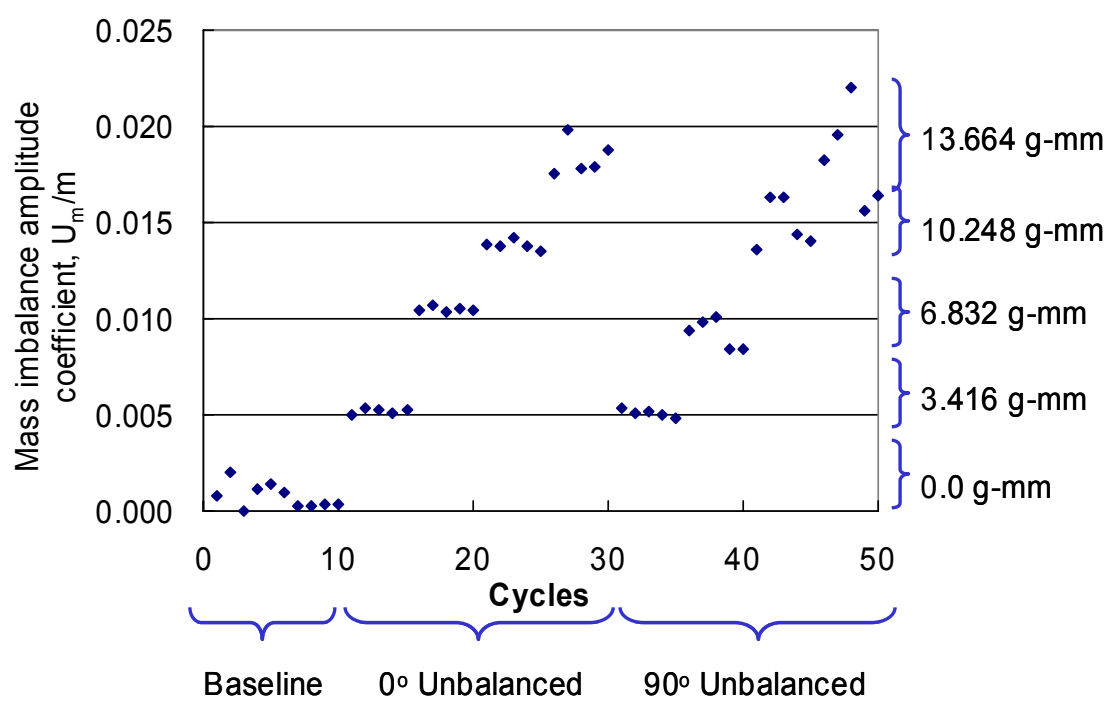

Figure 11.- Resonance-based identification-amplitude, vertical sensor.

The imbalance amplitude and phase results from the vertical sensor curve fitting are shown in figures 11 and 12. It is seen that the amplitude identifications are approximately linearly proportional to the added mass imbalance, while the phase identifications are very consistent at the same circumferential location. The standard deviation of phase identifications is $4.45^{\circ}$ at " 0 ' mass imbalance" and $2.95^{\circ}$ at " $90^{\circ}$ mass imbalance". For the first 10 baseline runs, the amplitudes identified are small and the phases tend to be random, as expected.

With known modal mass, the exact modal imbalance can be estimated without difficulty. For quick comparison, the identified parameters are scaled with respect to the mass imbalance at " 0 " " and " $90^{\circ}$ " at the smallest imbalance amount: $3.416 \mathrm{~g}-\mathrm{mm}$. The averaged scaled amplitudes are shown in figure 13. The percent change of the scaled amplitudes from that of the exact values is shown figure 14. For both circumferential locations, the percent changes are within 11 percent. 


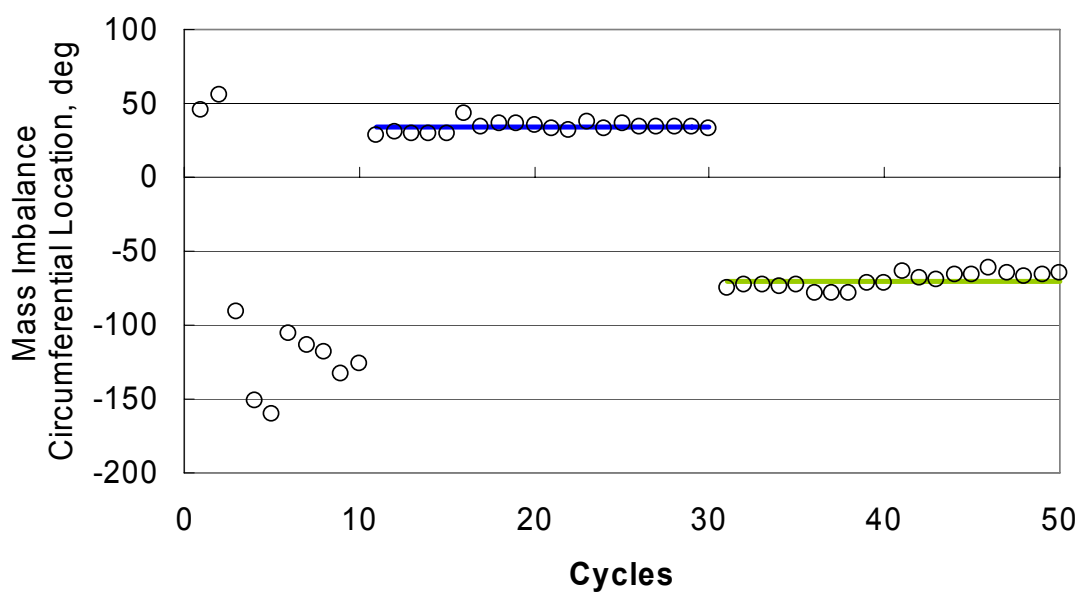

Figure 12.- Resonance-based identification-phase, vertical sensor.

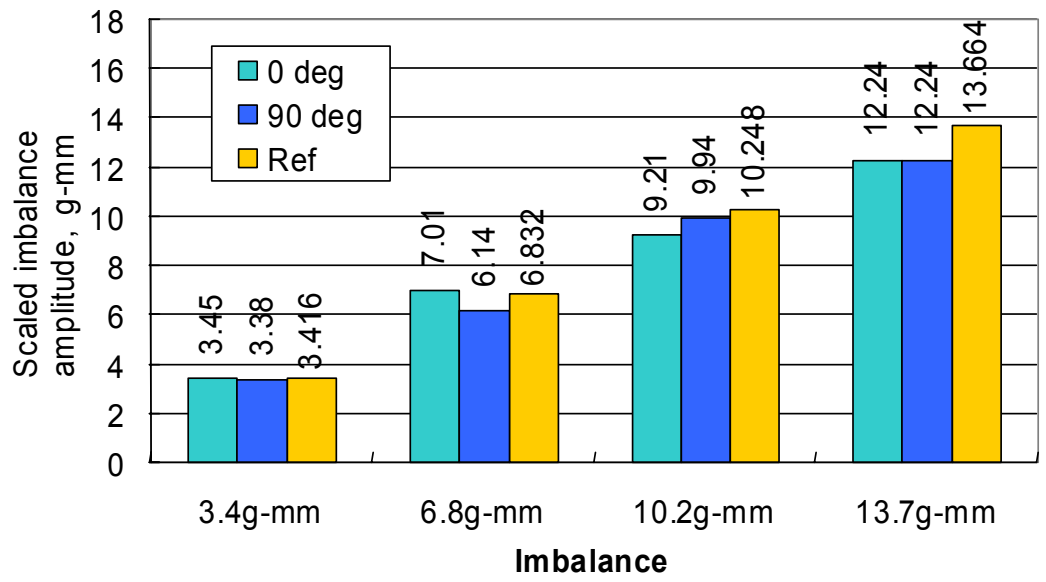

Figure 13.- Scaled amplitude factor, vertical sensor.

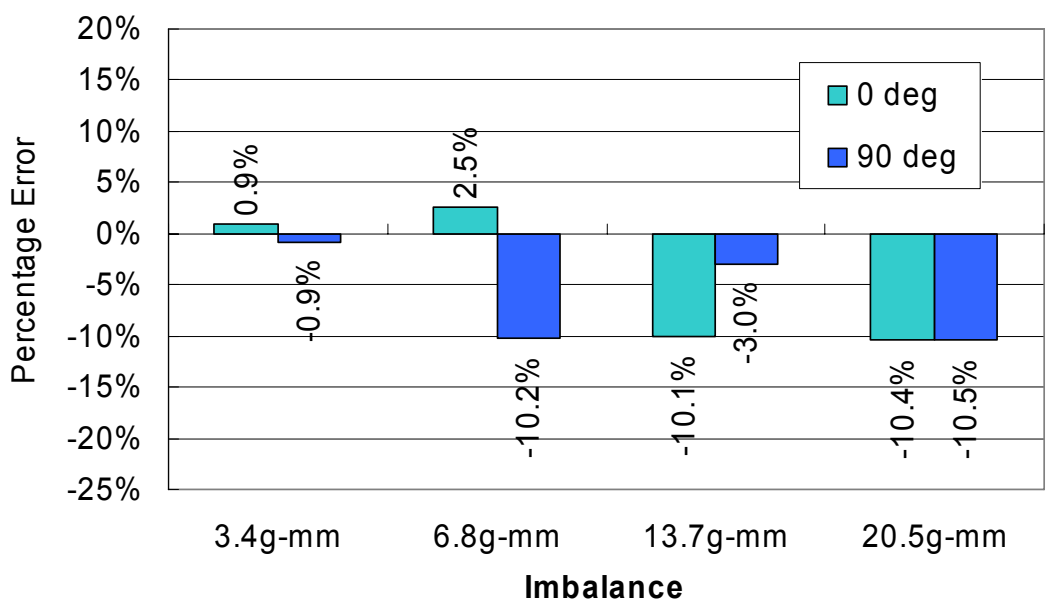

Figure 14.-Comparison of amplitude to baseline, vertical sensor. 
Similar data processing was carried out on the horizontal sensor. The results are shown in figure 15 to figure 18 . Similar results are achieved. The percent changes are less than 9 percent in this sensor.

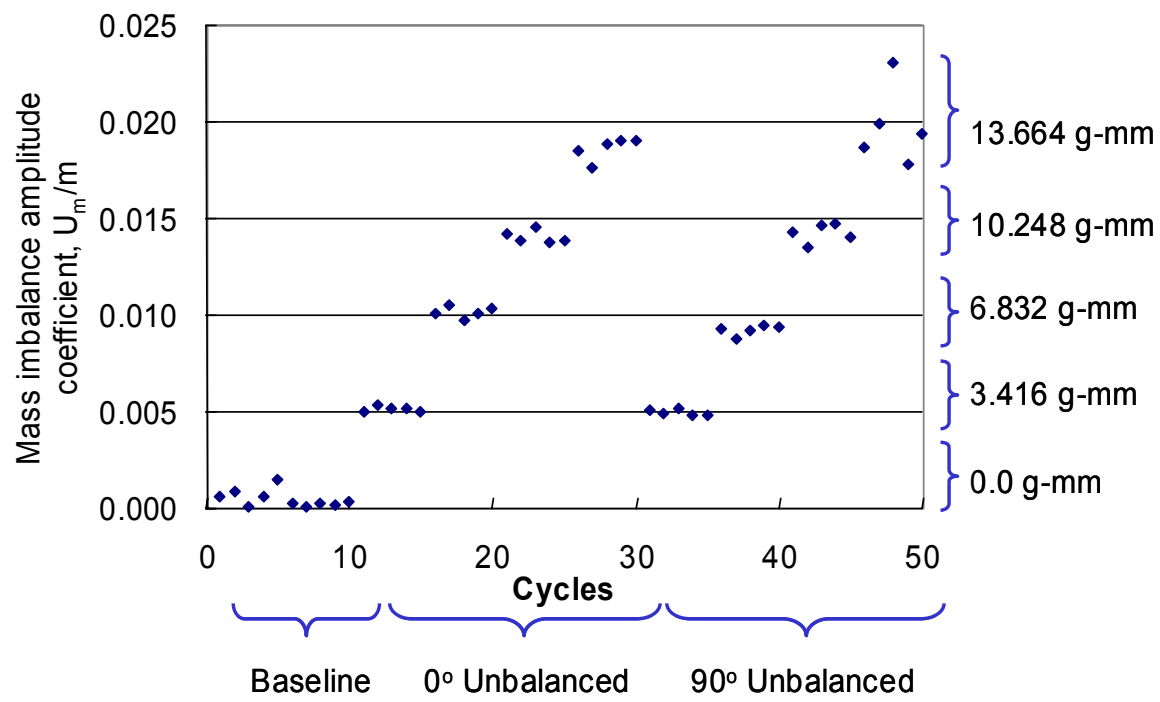

Figure 15.- Resonance-based identification-amplitude, horizontal sensor.

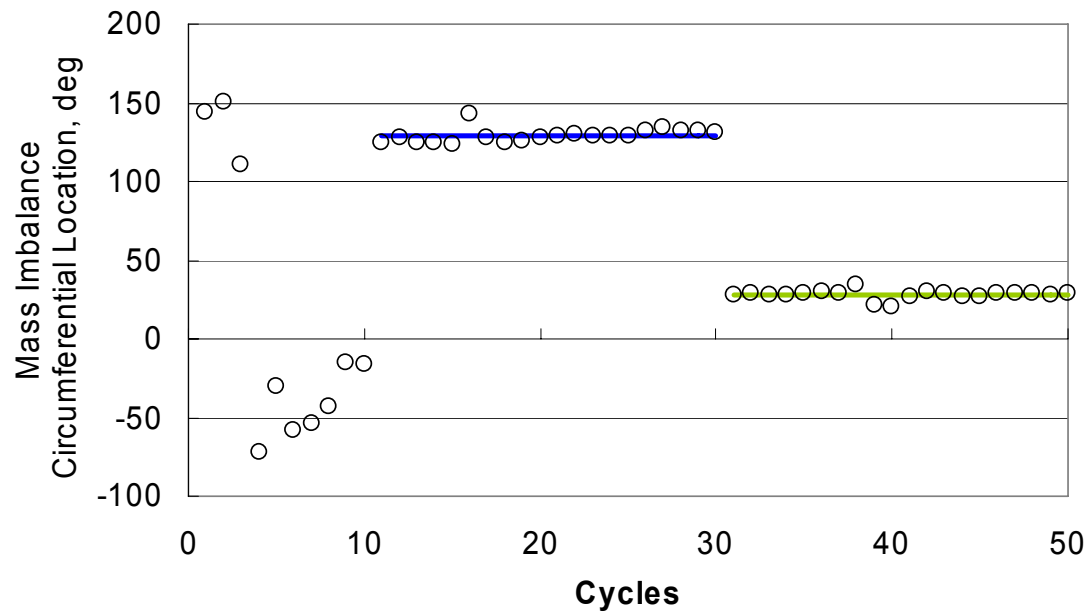

Figure 16.- Resonance-based identification-phase, horizontal sensor. 


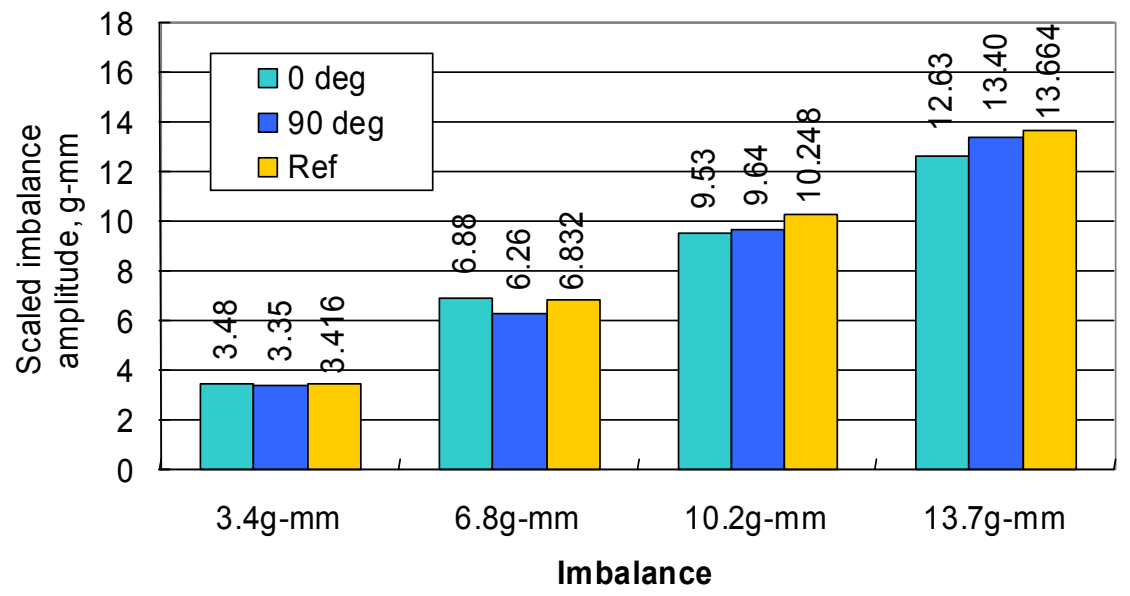

Figure 17.-Scaled amplitude factor, horizontal sensor.

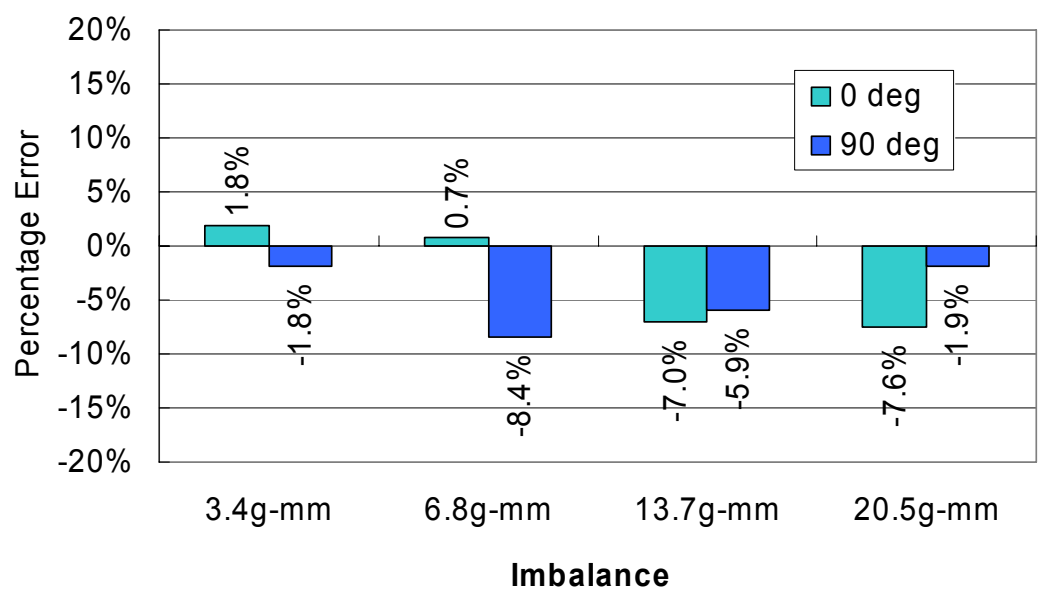

Figure 18. - Comparison of amplitude to baseline, horizontal sensor.

\section{Engine Test}

A seeded fault engine test was also performed to demonstrate various crack detection strategies on an Allison TF41-A1B engine (ref. 8) as shown in figure 19. The GE system used vibration sensors (accelerometers) mounted on the engine case. The detection algorithm introduced in section 2 was implemented and integrated into the system. The advantage of this system is that the sensors used either already exist in an engine system or can be easily installed.

The size and location for the initial fault seed was recommended by a stress analysis. It was determined that the location chosen was at a high stress area and the size and location of the slot was conducive to crack propagation (refer to fig. 20).

The initial crack was a flaw of 0.005 in wide by 0.100 in radius half penny notch into the surface by an electrodischarge machining (EDM) process. The seeded fault was pre-cracked at a spin pit. The initial fault on the fan disk was propagated from each tip of the seeded crack about 100 and 105 mils, respectively, before installing in the engine for test (fig. 21) (ref. 9). 


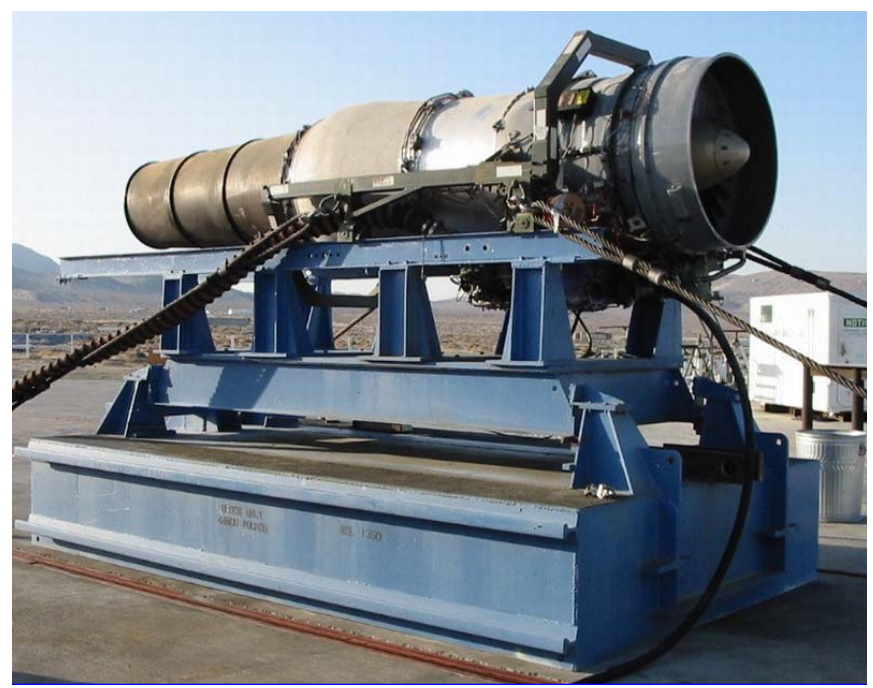

Figure 19.-Allison TF41-A1B engine on test stand.

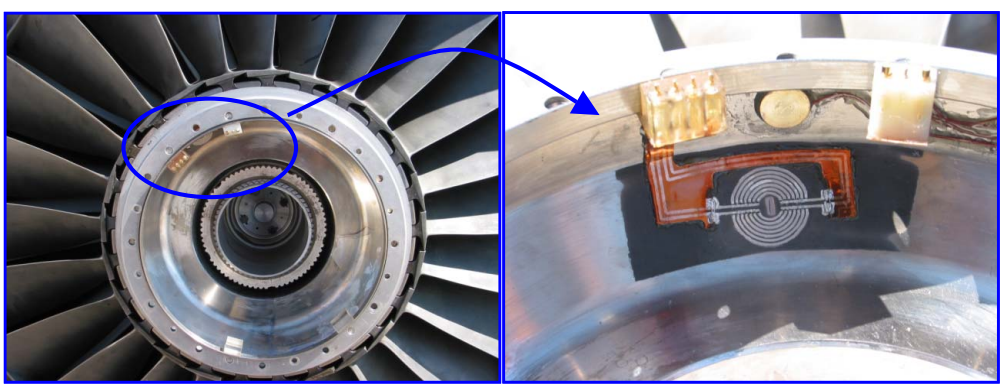

Figure 20.-Pre-cracked fan disk.

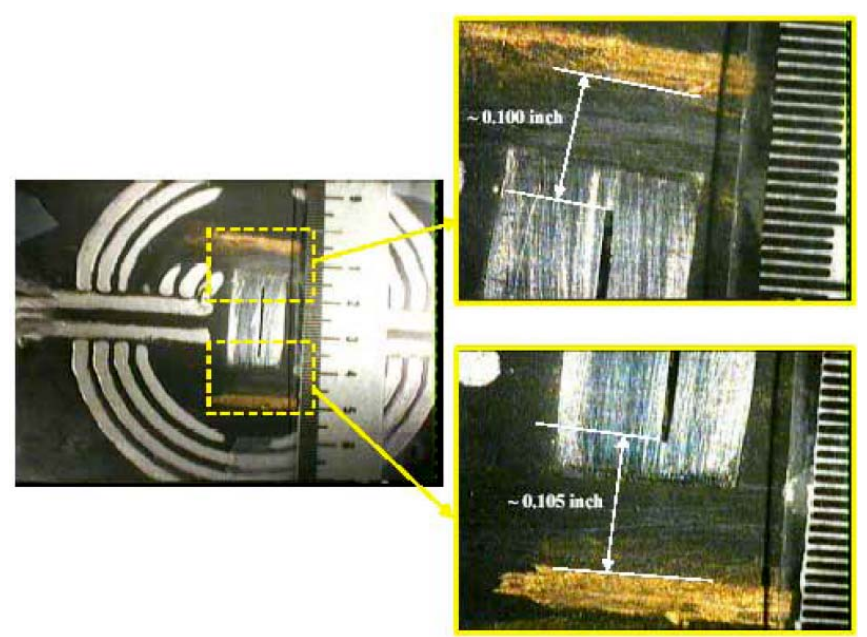

Figure 21.-Pre-cracked seeded fault. 


\section{A. Test Setup}

The GE system for this engine test used four accelerometers as sensors. The list of sensors is as following: sensor \#1: PCB 353B32, SN 83106, sensitivity 51.0mv/g; sensor \#2: PCB353B32, SN 83107, sensitivity 51.1mv/g; sensor \#3: PCB 353B04, SN 81329, sensitivity 10.48mv/g; sensor \#4: PCB 353B04, SN 81330, sensitivity $10.33 \mathrm{mv} / \mathrm{g}$.

Sensors \#1 and 2 were in the same plane as viewed from a cross section of the engine, and $90^{\circ}$ apart. Likewise, sensors \#3 and 4 were in the same plane and $90^{\circ}$ apart. The sensors were mounted on the 1 st stage stator case (fig. 22), where the vibrations from engine rotating parts can be best transmitted to the stationary engine case. Sensors \#1 and 2 were used as main sensors. Sensors \#3 and 4 were backups, in case of any overloading or other potential damages during the test. Sensor signals were conditioned at the test pad. The signal conditioners were protected by a steel cabin to prevent potential damage by an engine burst. The conditioned sensor signals were then transmitted to the control room for further on-line processing (fig. 23). A 1/rev tachometer signal and the acceleration signals were also recorded by a TEAC 8-channel digital tape recorder for future off-line analysis as needed (fig. 23).
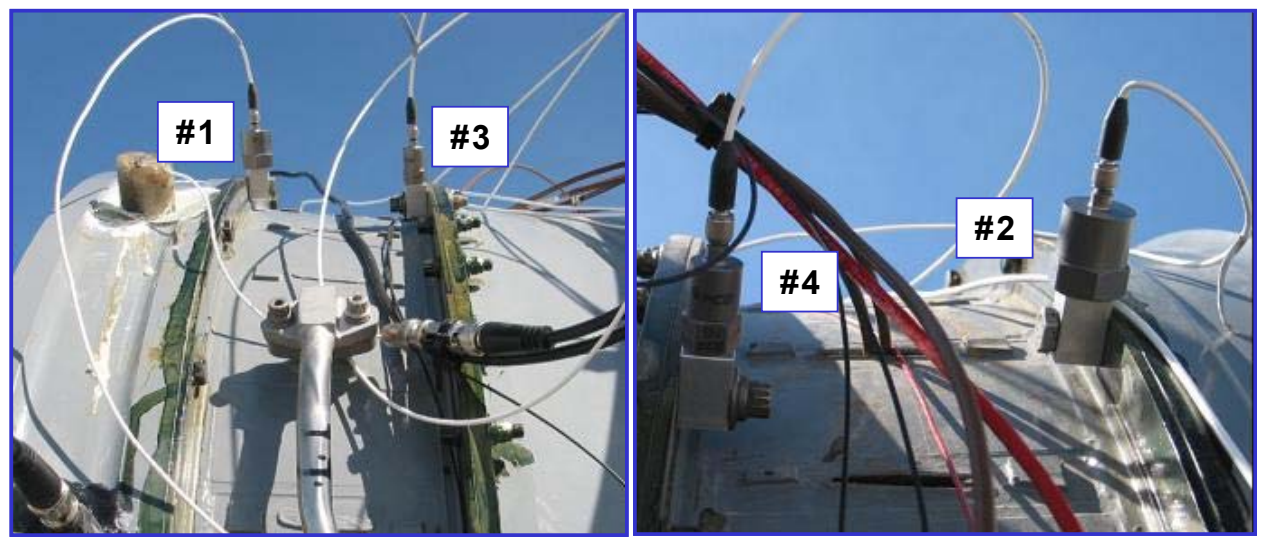

Figure 22.--Sensor locations.

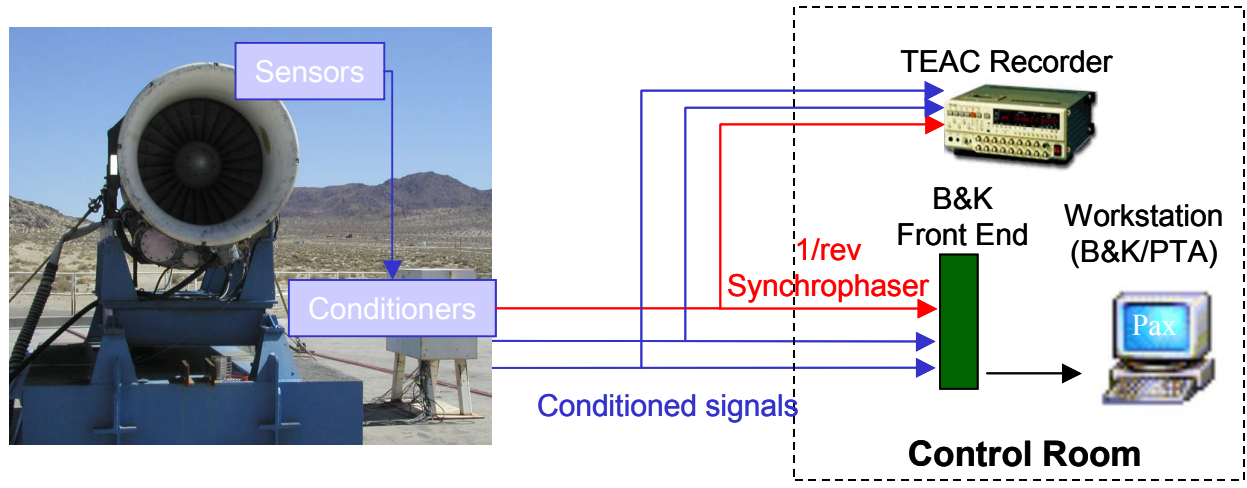

Figure 23.-Engine test system setup. 


\section{B. Data Processing}

The cycle profile used for the complete engine test was defined as: 27 short cycles plus one long cycle within half an hour. The short and long cycles are defined as:

- The longer cycle consisted of a $30 \mathrm{sec}$ dwell at idle, $75 \mathrm{sec}$ ramp up to the maximum speed (8000 rpm), $30 \mathrm{sec}$ dwell at the maximum speed, and a $15 \mathrm{sec}$ coast down to idle (approximately $2500 \mathrm{rpm}$ ) for a total cycle time of $150 \mathrm{sec}$.

- The shorter cycle consisted of a $15 \mathrm{sec}$ dwell at the idle, a $15 \mathrm{sec}$ ramp up to the maximum speed ( $8000 \mathrm{rpm})$, a $15 \mathrm{sec}$ dwell at the maximum speed, and a $15 \mathrm{sec}$ coast down to the idle $(2500 \mathrm{rpm})$ for a total cycle time of $60 \mathrm{sec}$.

After the first day test, all the detection systems participating in the testing found no significant crack propagation. To increase the crack growth rate, the team decided to increase the maximum speed to $8900 \mathrm{rpm}$.

Two weeks of testing finished with more than 4470 engine powered cycles without engine burst. The eddycurrent inspection of the crack revealed a crack length of $0.130 \pm 0.010$ in beyond the EDM notch on the outer diameter side of the EDM notch and $0.120 \pm 0.010$ in beyond the inner diameter side of the EDM notch on the disk (fig. 24). This implies an approximately 25 mils radius averaged growth after two weeks' testing.

Figure 25 shows an averaged synchronous vibration response amplitude for sensor \#1. Here, the most significant resonant peak is located at about $5000 \mathrm{rpm}$. Thus, the MDOF system response model as described from equations (7) through (10) was used. Just the portion near the most significant resonant peak (5000 rpm) was used and a curve-fitting was carried out. As shown in figure 26, where the top portion of the figure is displaying the amplitude results while the bottom portion is the phase results, the red circles are the raw data from measurement and the blue line the curve-fitting results. A good fitting can be achieved by using equation (10) and the proposed iteration method.
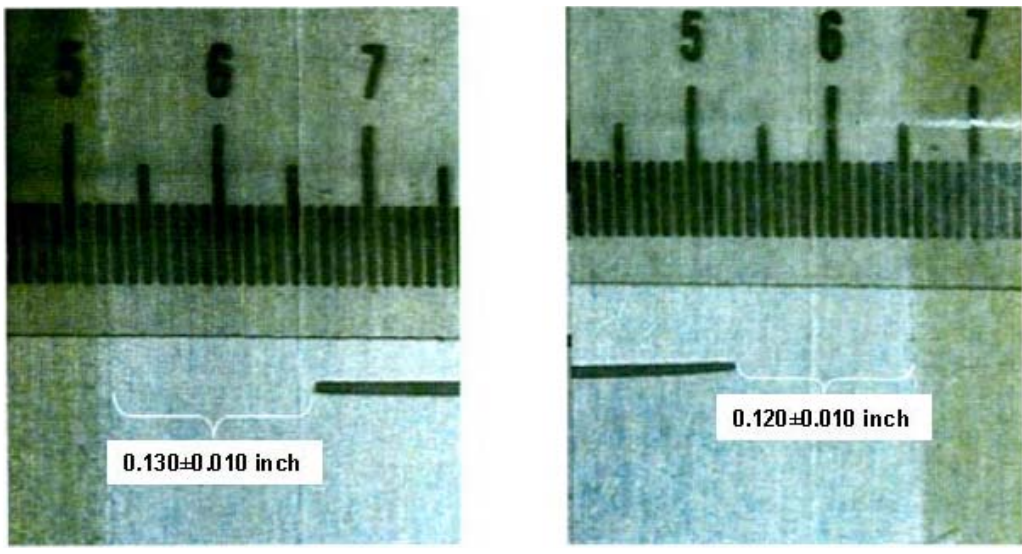

Figure 24.-Disk crack propagation after two weeks of testing. 


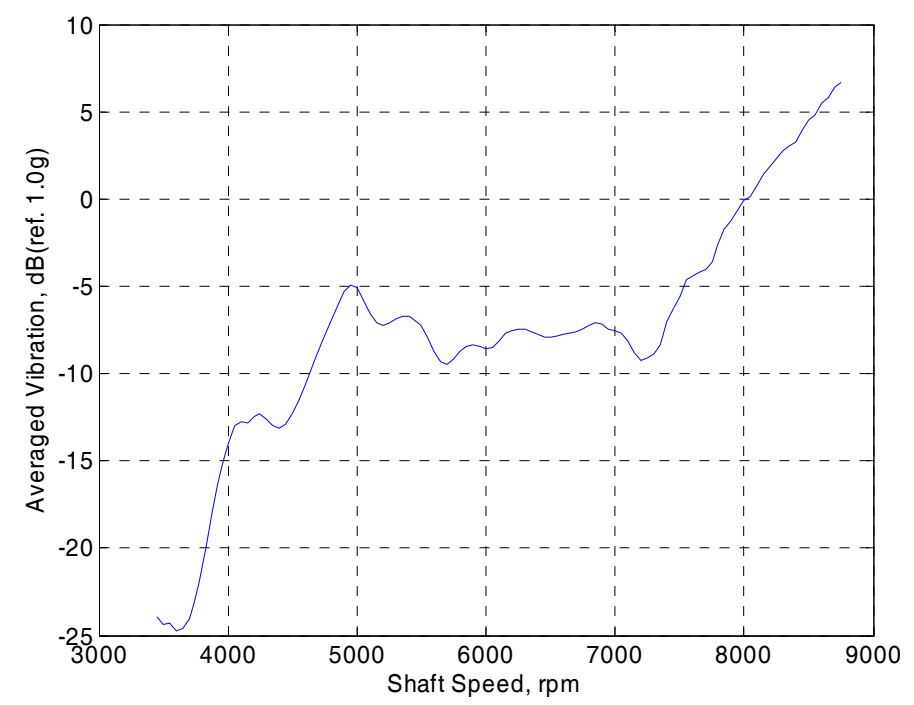

Figure 25.- Averaged synchronous vibration response - sensor \#1.
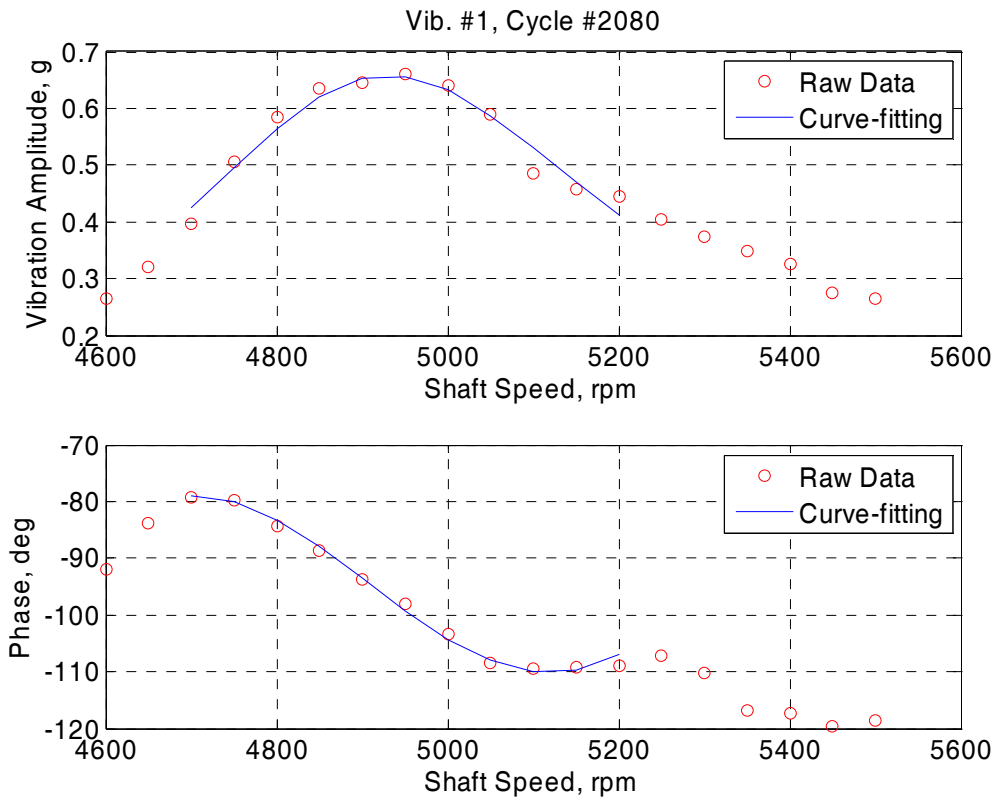

Figure 26.-Curve fitting results.

The identified mass imbalance term and the crack-induced term are shown in figure 27 . There are some cycles where the identified results are abnormal, largely due to imperfect data acquisition and diverging identification. Imperfect data acquisition usually happened after the starting up and shutting down of the engine.

To better reveal the trend of the imbalance identifications, the abnormal points are removed to form the "cleaned data". Then, a wavelet transformation technique was applied to the "clean data" to extract the long-term trend as well as day-to-day variational trends. A level 12 Daubechies wavelet was used in the transform. The overall trend and the day-to-day trend, together with the "cleaned data" are shown in figure 28. In figure 29, the overall trend and day-to-day variational trends are extracted and tagged with date marks.

As revealed in detail in figure 29, only minor increases happened in the over-all trend during the 2 weeks' testing. The day-to-day trend indicated the variation within a day, with a pattern of low-to-high-to-low. This is very likely due to dramatic daily temperature changes in the desert location where the tests were conducted.

Similar analyses on sensor \#2 can be found in figures 30 through 32 , where the overall trend is slightly decreased and the day-to-day trend exhibits the same variations in the trends from sensor $\# 2$. 

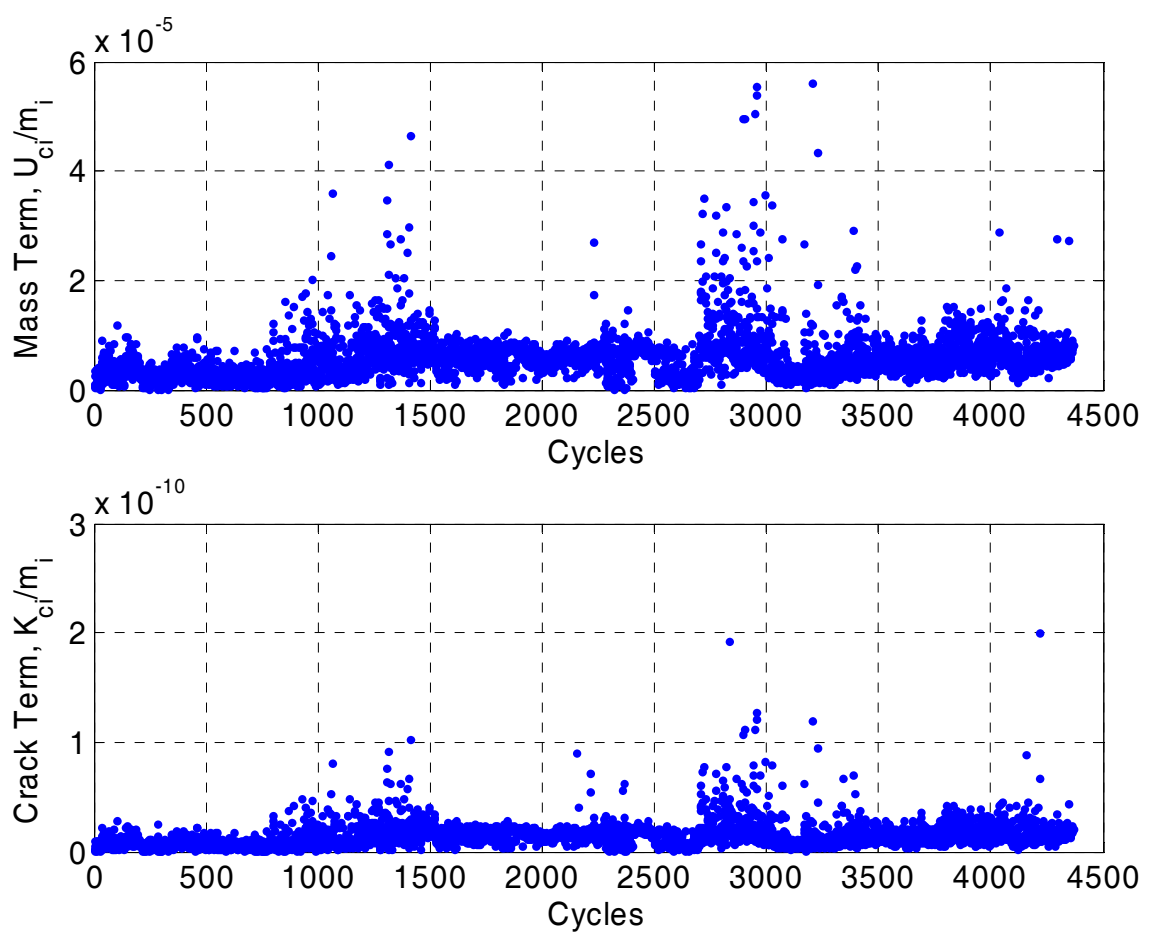

Figure 27.-Sensor \#1 identification results.
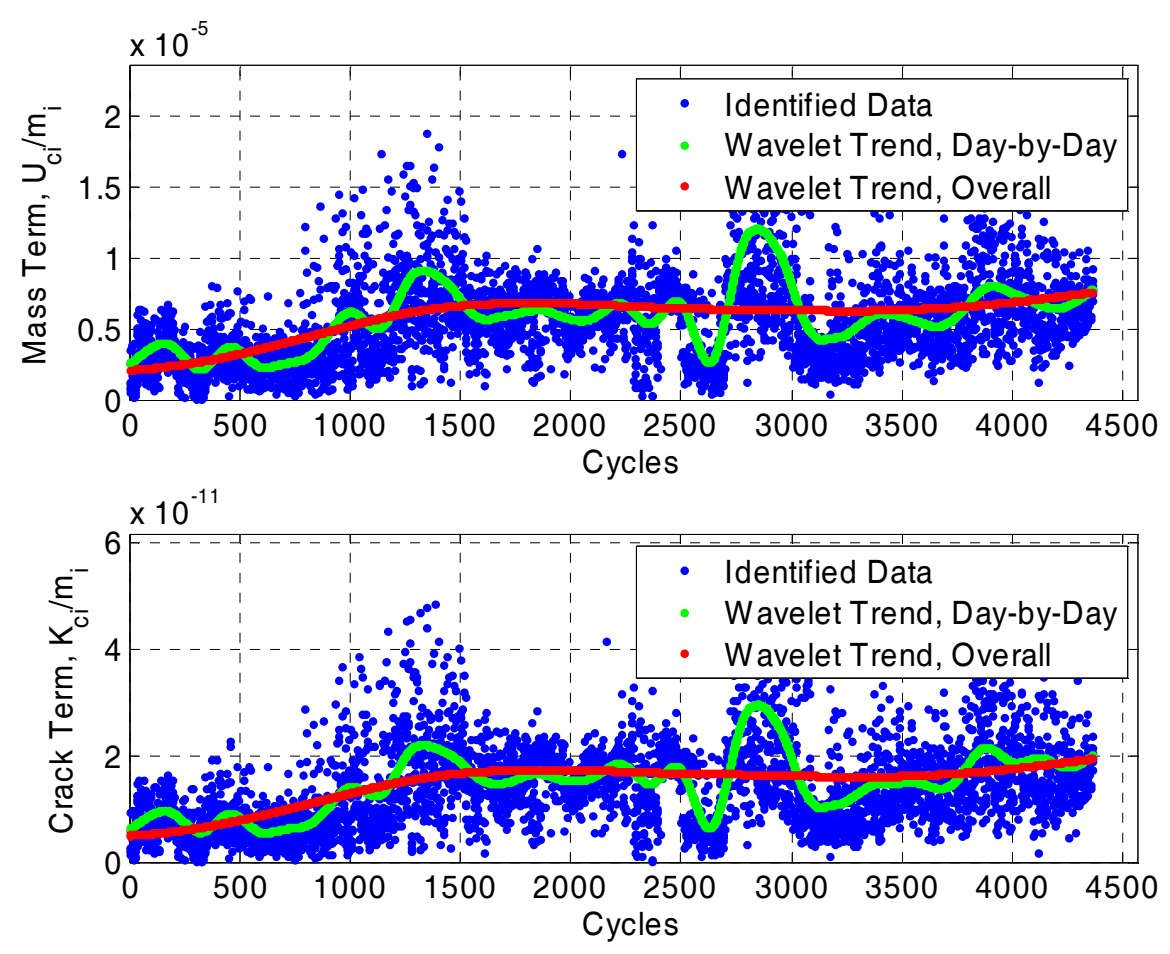

Figure 28. - Sensor \#1 abnormal removed data and trends. 

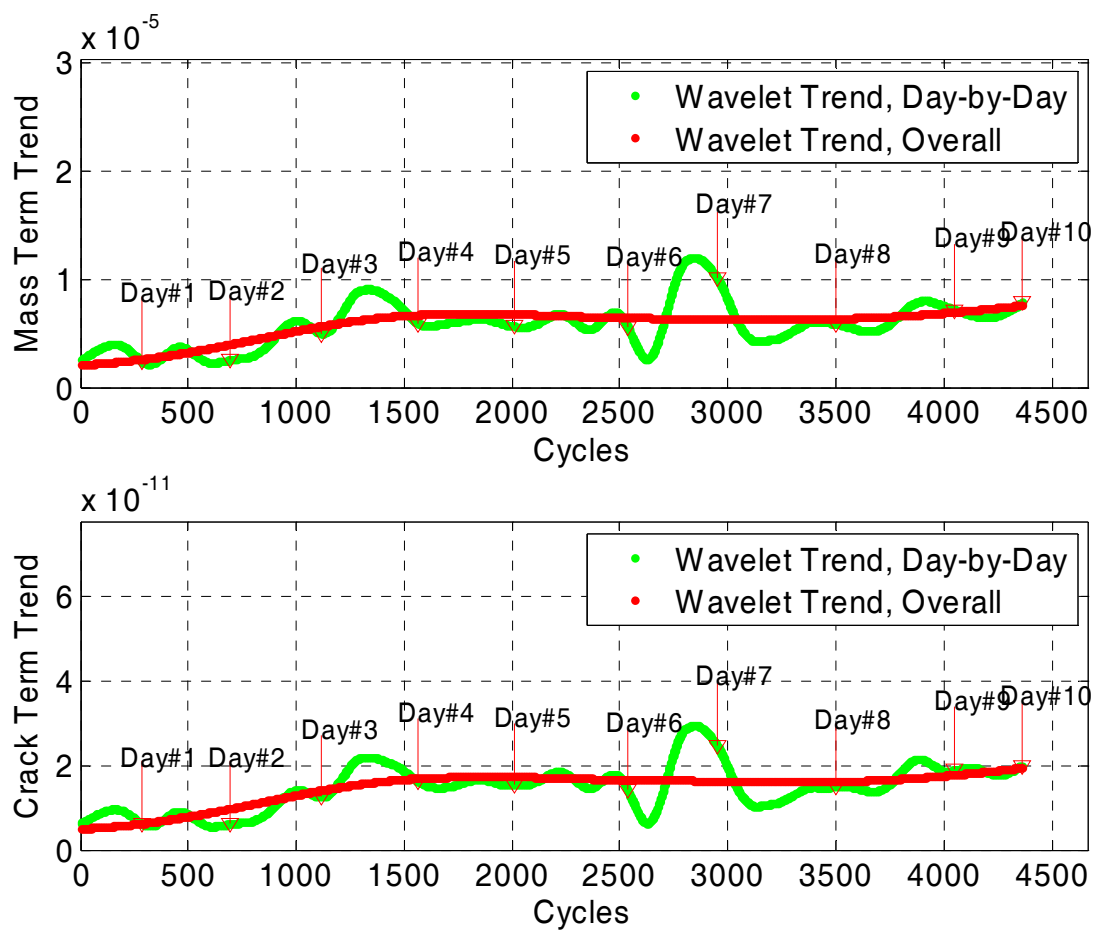

Figure 29.- Sensor \#1 overall trend and day-to-day trend.
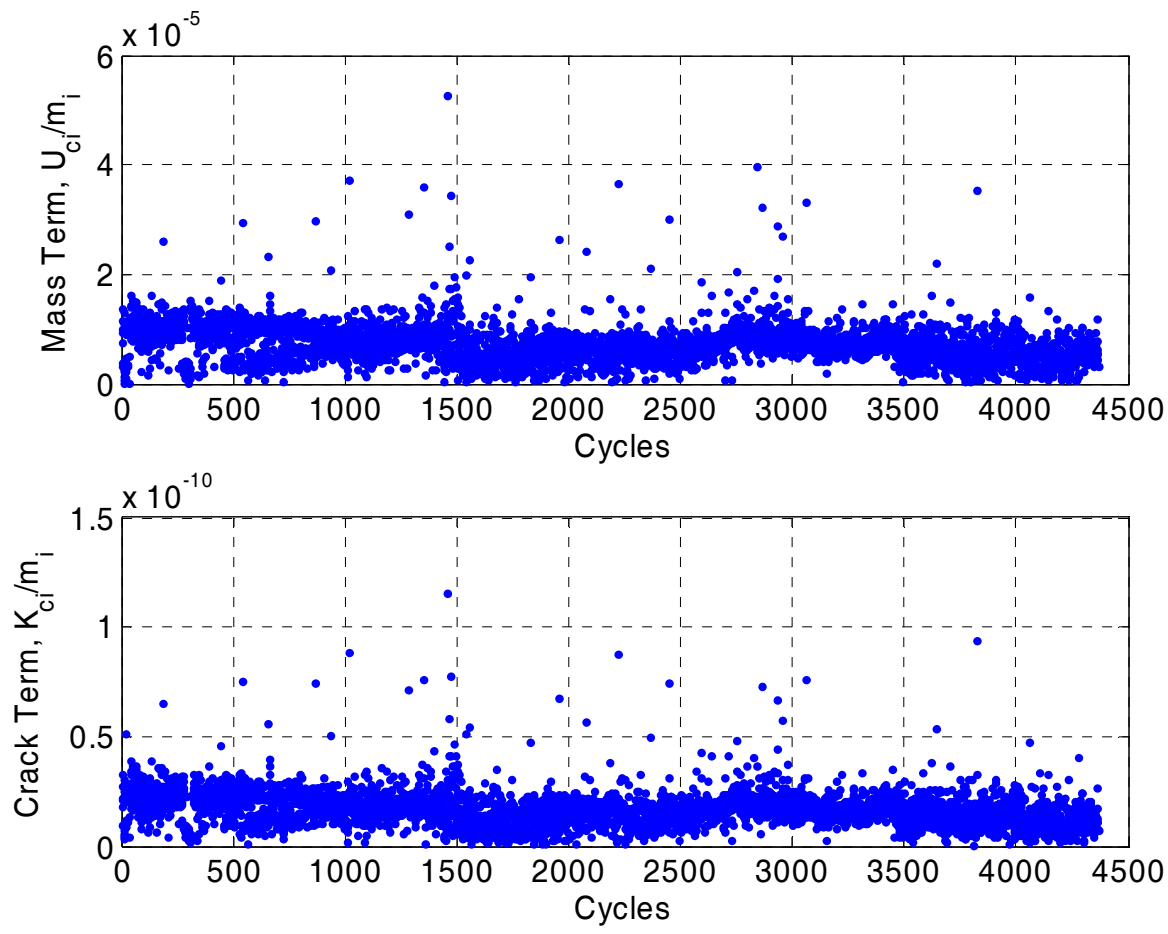

Figure 30.- Sensor \#2 identification results. 

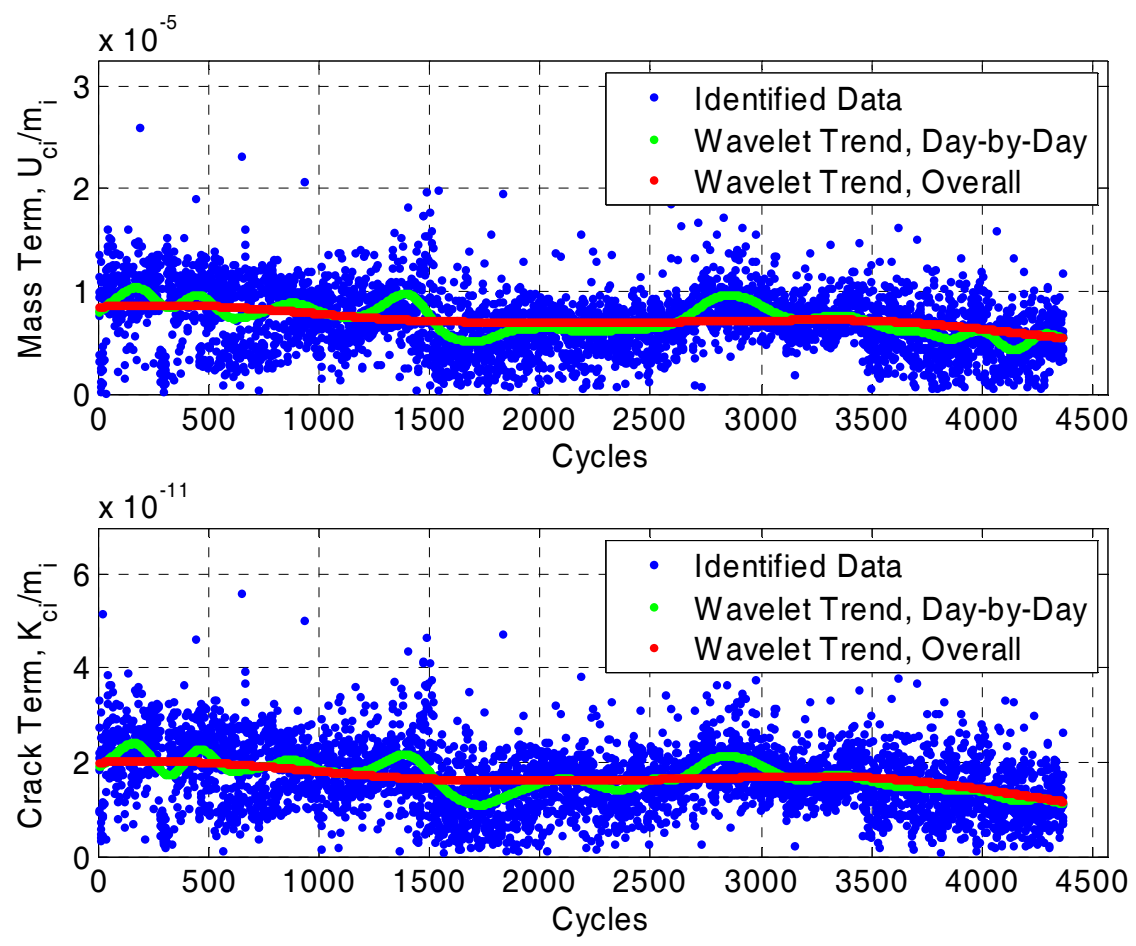

Figure 31. - Sensor \#2 abnormal removed data and trends.
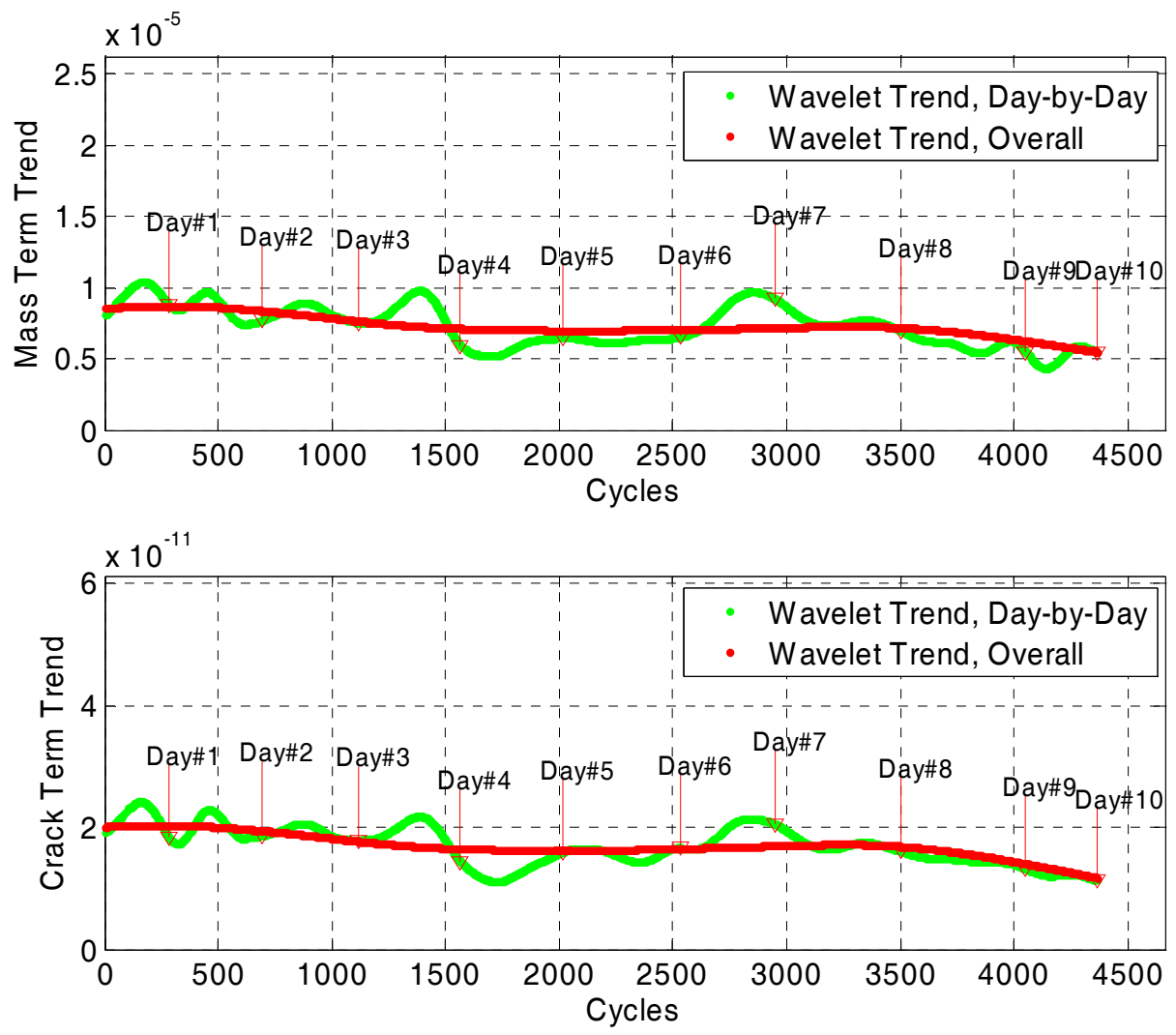

Figure 32.- Sensor \#2 overall trend and day-to-day trend. 


\section{Conclusions}

A method for rotor imbalance identification using rotor resonant synchronous vibration was presented. The imbalance is identified as a complex number through an iterative least-mean-square-based curve fitting technique. The magnitude of the identified complex number is the magnitude of the modal imbalance, while the phase of it is associated with imbalance location in the circumferential direction.

A complete data acquisition, data reduction, and data management system was integrated using state-of-the-art hardware and software. A MATLAB script was developed and interfaced with the system for real-time imbalance detections. A small rotor test rig was successfully used to validate the system integration and to examine the proposed algorithms.

The developed system was applied to a real engine test with embedded disk crack. The engine disk crack did not propagate into engine burst in the planned two weeks' testing. Though the crack did propagate for 45 mils, the crack growth was not large enough to be detected by the current method. The system data reduction using a wavelet transform did reveal minor day-to-day variations, which are very likely due to large temperature variation in the testing site.

Because of high signal-to-noise-ratio at resonance, the resonance-based algorithm is expected to have higher sensitivity than other vibration based method. It can be devised to use in health monitoring system for rotating machinery. It can also serve as an alternative for rotating machinery balancing. Further investigation of this technology is recommended.

\section{References}

1. Thomson W.T. and Dahleh, M.D., Theory of Vibration with Applications, 5th Ed., Prentice-Hall, Englewood Cliffs, New Jersey, 1998.

2. Tada H., Paris P., and Irwin G., The Stress Analysis of Cracks Handbook, 2nd Ed., Del Research Corp., St. Louis, Missouri ,1985.

3. NASA TM X-73307, Astronautics Structures Manual, vol. III (1975).

4. Imdad Imam and Horst G. DeLorenzi, "Method and apparatus for detecting axial cracks in rotors for rotating machinery," United States Patent \#4,751,657, June 14, 1988.

5. Eric Sonnichsen, "Real-time Detection of Developing Cracks in Jet Engine Rotors," Aerospace Conference Proceedings, 2000 IEEE, vol. 6, pp. 173-183, 2000.

6. Hector Rodriguez, Darren Hallman, Mark Butz, and Vikas Dhar, "A physics-based approach for the detection of cracks in rotating Disks," XV ISABE, 2001.

7. Huageng Luo, Hector Rodriguez, and Darren Hallman, "An Off-Resonance Synchronous Vibration Based Method for Rotor System Damage Detections," Journal of Mechanics of Materials and Structures, 2006.

8. David G. Lewicki, William C. Emmerling, Donald Altobelli, Silvia Seng, Chuck Frankenberger, and Leo Fila, "TF41 Engine Fan Disk Seeded Fault Crack Propagation Test," NASA/TM-2004-213092, May 2004.

9. Silvia Seng, "Turbine Engine Fan Disk Crack Detection Test," DOT/FAA/AR-04/28, September 2004. 
Public reporting burden for this collection of information is estimated to average 1 hour per response, including the time for reviewing instructions, searching existing data sources, gathering and maintaining the data needed, and completing and reviewing the collection of information. Send comments regarding this burden estimate or any other aspect of this collection of information, including suggestions for reducing this burden, to Washington Headquarters Services, Directorate for Information Operations and Reports, 1215 Jefferson Davis Highway, Suite 1204, Arlington, VA 22202-4302, and to the Office of Management and Budget, Paperwork Reduction Project (0704-0188), Washington, DC 20503.

\begin{tabular}{|l|l|l}
\hline 1. AGENCY USE ONLY (Leave blank) & $\begin{array}{c}\text { 2. REPORT DATE } \\
\text { August } 2006\end{array}$ & $\begin{array}{r}\text { 3. REPORT TYPE AND DATES COVERED } \\
\text { Technical Memorandum }\end{array}$
\end{tabular}

4. TITLE AND SUBTITLE

5. FUNDING NUMBERS

A Resonant Synchronous Vibration Based Approach for Rotor Imbalance

Detection

6. AUTHOR(S)

Huageng Luo, Hector Rodriguez, Darren Hallman, and David G. Lewicki

WBS

561581.02.07.03.03.05

$1 \mathrm{~L} 162211 \mathrm{~A} 47 \mathrm{~A}$

7. PERFORMING ORGANIZATION NAME(S) AND ADDRESS(ES)

8. PERFORMING ORGANIZATION

REPORT NUMBER

National Aeronautics and Space Administration

John H. Glenn Research Center at Lewis Field

Cleveland, Ohio 44135-3191

E-15570

9. SPONSORING/MONITORING AGENCY NAME(S) AND ADDRESS(ES)

National Aeronautics and Space Administration

Washington, DC 20546-0001

and

U.S. Army Research Laboratory

Adelphi, Maryland 20783-1145
10. SPONSORING/MONITORING AGENCY REPORT NUMBER

NASA TM-2006-214335

AIAA-2006-1966

ARL-TR-3908

11. SUPPLEMENTARY NOTES

Prepared for the 47th Structures, Structural Dynamics, and Materials Conference cosponsored by the AIAA, ASME, ASCE, AHS, and ASC, Newport, Rhode Island, May 1-4, 2006. Huageng Luo, Hector Rodriguez, and Darren Hallman, GE Global Research Center, Niskayuna, New York, 12309; David G. Lewicki, U.S. Army Research Laboratory, NASA Glenn Research Center. Responsible person, David G. Lewicki, organization code RXM, 216-433-3970.

\begin{tabular}{|l|l|l|l|l|}
\hline 12a. DISTRIBUTION/AVAILABILITY STATEMENT & DISTRIBUTION CODE
\end{tabular}

Unclassified - Unlimited

Subject Category: 37

Available electronically at http://gltrs.grc.nasa.gov

This publication is available from the NASA Center for AeroSpace Information, 301-621-0390.

13. ABSTRACT (Maximum 200 words)

This paper presents a methodology of detecting rotor imbalances, such as mass imbalance and crack-induced imbalance, using shaft synchronous vibrations. An iterative scheme is developed to identify parameters from measured synchronous vibration data. A detection system is integrated by using state-of-the-art commercial analysis equipment. A laboratory rotor test rig is used to verify the system integration and algorithm validation. A real engine test has been carried out and the results are reported.

\section{SUBJECT TERMS}

\begin{tabular}{|l|l|}
\hline & $\begin{array}{c}15 . \text { NUMBER OF PAGES } \\
26\end{array}$ \\
\cline { 2 - 2 } & 16. PRICE CODE \\
\hline $\begin{array}{c}\text { 19. SECURITY CLASSIFICATION } \\
\text { OF ABSTRACT } \\
\text { Unclassified }\end{array}$ & 20. LIMITATION OF ABSTRACT \\
\hline
\end{tabular}

NSN 7540-01-280-5500

Standard Form 298 (Rev. 2-89) 

